NBER WORKING PAPER SERIES

\title{
PREMIUM TRANSPARENCY IN THE MEDICARE ADVANTAGE MARKET: IMPLICATIONS FOR PREMIUMS, BENEFITS, AND EFFICIENCY
}

\author{
Karen Stockley \\ Thomas McGuire \\ Christopher Afendulis \\ Michael E. Chernew \\ Working Paper 20208 \\ http://www.nber.org/papers/w20208 \\ NATIONAL BUREAU OF ECONOMIC RESEARCH \\ 1050 Massachusetts Avenue \\ Cambridge, MA 02138 \\ June 2014
}

This research was supported by a grant from the National Institute on Aging (Grant No. P01 AG032952), and by the Marshall J. Seidman Program in Health Economics in the Department of Health Care Policy at Harvard Medical School. Stockley gratefully acknowledges support from the National Science Foundation Graduate Research Fellowship under Grant No. DGE-1144152. The views expressed herein are those of the authors and do not necessarily reflect the views of the National Bureau of Economic Research.

At least one co-author has disclosed a financial relationship of potential relevance for this research. Further information is available online at http://www.nber.org/papers/w20208.ack

NBER working papers are circulated for discussion and comment purposes. They have not been peerreviewed or been subject to the review by the NBER Board of Directors that accompanies official NBER publications.

(C) 2014 by Karen Stockley, Thomas McGuire, Christopher Afendulis, and Michael E. Chernew. All rights reserved. Short sections of text, not to exceed two paragraphs, may be quoted without explicit permission provided that full credit, including (C) notice, is given to the source. 
Premium Transparency in the Medicare Advantage Market: Implications for Premiums, Benefits, and Efficiency

Karen Stockley, Thomas McGuire, Christopher Afendulis, and Michael E. Chernew

NBER Working Paper No. 20208

June 2014

JEL No. I11

\begin{abstract}
In the Medicare Advantage (MA) market, private health insurers compete to offer plans with the most attractive premium and benefit package. Medicare provides a subsidy, based on a "benchmark payment rate", for each Medicare beneficiary a plan enrolls. We investigate how this subsidy, the primary policy lever in the market, affects the equilibrium premiums and benefits of MA plans. We exploit variation in benchmark payment rates within plans over time, coming from rebasing years where benchmark changes differed across areas in ways that were plausibly exogenous, to determine empirically how plan premiums and benefit generosity respond to changes in benchmarks. We find that premiums do not respond to changes in the benchmark payment rate on average but that insurers do pass through a portion of the benchmark increase by increasing plan benefit generosity.

We argue that the way premium information is communicated to consumers influences the way in which plans pass through subsidy dollars and can account for the empirical results. More specifically, institutional features make it difficult for consumers to observe a large component of the plan premium, leading to a lack of demand response to premium reductions below the premium charged by traditional Medicare (the fee-for-service Part B premium). When demand does not respond to lower premiums, plans have an incentive to pass-through cost subsidies to consumers via more generous benefits that consumers may not value at cost, creating an inefficiently high level of benefit generosity. Our results provide evidence that a lack of premium transparency in the MA market may distort the combination of premium levels and benefit generosity offered in equilibrium, resulting in some degree of inefficiently high benefits. We conclude by discussing changes to the choice environment that would increase premium transparency and potentially soften the premium rigidities we find.
\end{abstract}

Karen Stockley
Department of Economics
Harvard University
kstockley@fas.harvard.edu
Thomas McGuire
Department of Health Care Policy
Harvard Medical School
180 Longwood Avenue
Boston, MA 02115
and NBER
mcguire@hcp.med.harvard.edu

\author{
Christopher Afendulis \\ Department of Health Care Policy \\ Harvard Medical School \\ 180 Longwood Avenue \\ Boston, MA 02115 \\ afendulis@hcp.med.harvard.edu \\ Michael E. Chernew \\ Harvard Medical School \\ Dept. of Health Care Policy \\ 180 Longwood Avenue \\ Boston, MA 02115 \\ and NBER \\ chernew@hcp.med.harvard.edu
}




\section{Introduction}

The Medicare program provides health insurance coverage to nearly 50 million aged and disabled individuals in the United States. Medicare beneficiaries have the option of enrolling in a private health insurance plan through the Medicare Advantage (MA) market as an alternative to traditional, fee-for-service (FFS) Medicare coverage. In 2013, 29\% of beneficiaries chose to enroll in an MA plan (Gold et al., 2013). These private plans are heavily subsidized by Medicare, with the federal government spending $\$ 123$ billion in payments to these plans in 2012 (Congressional Budget Office, 2013), an amount estimated to be $7 \%$ greater than what the government would have spent on care for these beneficiaries had they chosen to remain in FFS Medicare in that year (Medicare Payment Advisory Commission, 2012).

Insurers have considerable flexibility in designing plans to offer on the MA market. Plans differ in the premium charged to consumers, the provider network, and the benefit generosity, provided the benefits are at least as generous as those in FFS Medicare. Plan choices over these dimensions determine the menu of plans available to consumers in an area. The key policy lever available to the government to influence plan premiums, benefits, and enrollment is the "benchmark payment rate" or simply the benchmark. Prior studies have shown that higher benchmark payment rates are associated with higher enrollment and a greater number of plans participating in the MA market (McGuire et al., 2011). However, little is known about how higher benchmark payments are divided among lower premiums, more generous benefits, and higher plan profits, and whether the division is efficient.

This paper makes two contributions. First, we estimate the response of plan premiums and benefit generosity to changes in benchmark payment rates. Changes to benchmark payment rates

are frequently discussed as a means of controlling Medicare Advantage program costs, and the way in which these changes affect premiums and benefit generosity are a first-order concern. Understanding how government subsidies influence equilibrium premiums and benefit generosity in private insurance markets is also of interest for understanding competitive outcomes in both the MA market and other regulated, subsidized markets for private health insurance including the new state insurance exchanges established under the Affordable Care Act. To estimate how plan premiums and benefit generosity respond to changes in benchmarks we exploit variation in benchmark payment rates within plans over time, coming from payment "rebasing" years when benchmark changes differed across areas in ways that were plausibly exogenous. We find that on average plan premiums do not respond to increases in benchmark payment rates, but that benefits do increase.

Second, we identify an important feature of the choice environment that explains why plans pass on additional subsidy dollars in the form of more generous benefits, rather than lower premiums. As we explain in more detail later, FFS Medicare and MA plan premiums are presented to beneficiaries 
in such a way that plan premium reductions below the level of the premium charged by FFS Medicare, known as the Part B premium, are not salient to consumers, leading to a sharp drop-off in the premium elasticity of demand at this point. This behavior can be represented with a demand curve "kinked" at the FFS Medicare Part B premium. The kinked demand model implies that profit maximizing MA plans price at the kink, for a wide range of marginal costs, benchmark payment rates, and consumer preferences. Consistent with this theory, more than half of MA plans charge a premium exactly equal to the FFS Medicare Part B premium. We argue that this institutional feature causes premiums to under-respond to changes in benchmarks and creates incentives for some consumers to select plans with inefficiently high premiums and benefits. We conclude by discussing simple and inexpensive changes to the choice environment that would increase premium transparency.

The remainder of the paper proceeds as follows. First, we summarize the relevant institutional features of the MA market and relevant prior literature. Second, we establish predictions from two simple models of the expected response of premiums and benefit generosity to changes in benchmark payment rates to aid in interpreting our empirical results. Next, we describe our empirical strategy and results. Finally, we discuss the implications of our results and conclude.

\section{Background}

\subsection{Medicare Advantage}

The 1982 Tax Equity and Fiscal Responsibility Act authorized Medicare to begin risk-based contracting with private insurers in 1985 under the Medicare+Choice program. Under this program, now known as Medicare Advantage (MA), the Center for Medicare and Medicaid Services (CMS) contracts with insurers, and those insurers offer plans with varying degrees of premiums and benefits to Medicare beneficiaries. Medicare pays these plans prospectively, and plans assume full responsibility for the covered costs incurred by enrollees. Beneficiaries have the option of enrolling in a private plan or remaining in traditional, fee-for-service (FFS) Medicare. Private plan enrollment was low in the early years of the program but has increased dramatically over time as a result of a variety of changes to the program's structure and payment generosity. In 2013 , $29 \%$, or 15 million, Medicare beneficiaries were enrolled in a private plan, compared to $17 \%$, or 7 million, in 2000 (Gold et al., 2012, 2013). The goals of the MA program are twofold. One goal is to give beneficiaries choice in their health plan, a departure from the previous regime where all beneficiaries received coverage through the government-run traditional FFS Medicare plan. The second goal is to increase efficiency in the provision of Medicare benefits and decrease costs in the Medicare program (McGuire et al., 2011). 
The 2003 Medicare Prescription Drug, Improvement, and Modernization Act (MMA) changed the payment scheme from a uniform capitation rate for all plans with the same service area to one where plans receive different capitation rates based on their bids. ${ }^{1}$ The current payment scheme works as follows. Each year Medicare sets county-level benchmark payment rates, which were originally intended to reflect the expected cost of covering an average beneficiary under FFS Medicare in that area. Plans then submit a bid, representing what they will accept to provide an actuarial equivalent of the standard benefit package covered under FFS Medicare. ${ }^{2}$ Plans can elect to provide more generous benefits, on top of the standard benefit package, for which they may charge a premium. Medicare pays plans the lower of the plan bid and the benchmark payment rate for the plan's service area. ${ }^{3}$ Plans bidding below the benchmark also receive an additional "rebate" payment equal to a fixed percent of the difference between their bid and the benchmark that they are required to return to their enrollees in the form of a reduced premium or a more generous benefit structure. Prior to 2011 plans received $75 \%$ of the difference as a rebate payment, but since 2012 the percent of the difference rebated to plans depends on the plan's quality rating, as specified in the Affordable Care Act. Beginning in 2014, the rebate percentage is now either $50 \%, 65 \%$, or $70 \%$ with higher quality plans receiving higher rebate percentages. ${ }^{4}$

The total premium charged to consumers for an MA plan has three components. The first is the Part B premium, which goes toward the standard benefits package that all MA plans are required to cover. All Medicare beneficiaries, whether they elect to enroll in an MA plan or traditional FFS Medicare, pay a Part B premium. ${ }^{5}$ The Part B premium under FFS Medicare was $\$ 96.40$ from 2008-2010 and $\$ 104.90$ in 2013, but MA plans can choose to charge a lower Part B premium than the one charged under FFS Medicare. ${ }^{6}$ Although MA plans are able to charge a lower premium than the FFS Medicare premium, the mechanism for doing so is somewhat convoluted. Plans may charge a premium below the FFS premium by "buying down" the Part B premium, which consists of paying CMS to reduce the Part B premium amount the enrollee is obligated to pay CMS. For reasons described below, this "buy down" may not be transparent to consumers. The other two components of the MA premium are the Part $\mathrm{C}$ premium, which goes toward any additional medical

\footnotetext{
${ }^{1}$ We use the word "bid" to be consistent with the language of the MA program, however these are not bids in the sense of a traditional auction. Even the plan with the highest bid is allowed to enter the market.

${ }^{2}$ The bid is supposed to equal the plan's cost of providing the standard benefits package covered under FFS Medicare, plus a profit margin. However, plans have some flexibility in how they report costs. The allowable profit margin varies by insurer as it is based on the insurer's rate-of-return in its non-MA business. It is required to fall within a plan or contract-specific range according to a complicated formula. CMS refers to the profit margin as the "gain/loss margin" and the allowed profit threshold as the plan sponsor's "corporate requirement". Allowable profit margins are consistent over time and across plan types.

${ }^{3}$ The payments are risk adjusted to reflect the varying health status of the plan's enrollee pool. See Newhouse et al. (2011).

${ }^{4}$ Quality-adjusted benchmark payment levels were phased in beginning in 2012 (Medicare Payment Advisory Commission, 2011).

${ }^{5}$ There are a few rare circumstances where FFS beneficiaries do not pay the Part B premium.

${ }^{6}$ Beginning in 2007, higher income Medicare beneficiaries pay a higher Part B premium.
} 
benefits the plan chooses to offer, and the Part D premium, which goes toward any prescription drug benefits the plan chooses to offer. In sum, the total consumer premium for enrolling in traditional FFS Medicare is equal to the Part B premium (plus an additional Part D premium for beneficiaries that also enroll in a stand alone prescription drug plan through the "Part D only" market), and the total consumer premium for enrolling in an MA plan (with drug coverage) is equal to the sum of the Parts B, C, and D premiums charged by the MA plan. ${ }^{7}$

CMS imposes two relevant constraints on the plan's choice of its premium and benefit package. First, the rebate payment must be allocated toward either offsetting the cost of additional benefits, or reducing the plan premium. ${ }^{8}$ Second, the total cost of the plan's additional benefits must equal the sum of the Parts C and D premiums, net of any Part B buy down, plus the rebate dollars allocated toward additional benefits. In other words, if the plan's bid was equal to the benchmark and the plan charged a zero Part C and D premium the plan could not offer any additional benefits beyond the standard benefits package. The rebate provides the only incentive for plans to bid low, because plans can use rebate dollars to make their products more attractive to consumers. These constraints are intended to limit insurer profits and ensure that consumers capture surplus due to benchmarks that exceed plan costs via more generous benefits or lower premiums. ${ }^{9}$ As a result of these constraints, the rebate, premium, and benefit generosity are related by the following identity: $b=$ rebate $+p$, where $b$ is additional benefits and $p$ is the sum of the Parts $\mathrm{C}$ and $\mathrm{D}$ premiums, net of any Part B buy down (negative $p$ 's are possible).

The most common MA plan premium has a Part B premium equal to the FFS Medicare Part B premium, and Part $\mathrm{C}$ and $\mathrm{D}$ premiums set at $\$ 0$. Roughly half of consumers are enrolled in these "zero" premium plans and only $5 \%$ of consumers are enrolled in plans with Part B premiums below the FFS Part B premium. ${ }^{10}$ A plot of the premium distribution in 2008, shown in Figure 1, makes the extent of clustering at the $\$ 96.40$ FFS Part B premium clear. An economic analysis of MA plan behavior should account for this clustering at "zero" for premiums that can fall along a continuum.

Medicare beneficiaries enroll in MA plans in one of two ways. First, they can search for all plans available in their market through the online Medicare Plan Finder. On the initial page of search results, consumers will see the following pieces of information about each plan: the estimated annual drug cost, the estimated annual drug plus health costs, the monthly premium, the deductible(s)

\footnotetext{
${ }^{7}$ The vast majority of MA plans offer drug coverage. In our sample, over $90 \%$ of consumers are enrolled in an MA plan with drug coverage.

${ }^{8}$ Costs include both the direct claims paid by the plan as well as administrative costs, such as claims processing. The cost can also include a small profit margin.

${ }^{9}$ The degree to which CMS is able to enforce these constraints is unknown. All insurers are required to provide provide actuarial justification that they have met these constraints during the annual bid submission process and may be audited. Because plans repeatedly contract with Medicare, CMS may partially enforce these constraints by allowing only limited variation in a plan's reported costs and actuarial assumptions from year to year.

${ }^{10} \mathrm{~A}$ plan must have a $\$ 0$ Part $\mathrm{C}$ and $\mathrm{D}$ premium before it can buy down the Part B premium.
} 
and copay or coinsurance amounts, whether the plan restricts doctor choice, the OOP spending limit, drug coverage restrictions, and a plan quality rating. Importantly, the monthly premium displayed includes only the Parts $\mathrm{C}$ and $\mathrm{D}$ premium. It does not include the Part B premium, note any reduction in the Part $\mathrm{B}$ premium the plan offers, or even note that the consumer will be required to pay a Part $\mathrm{B}$ premium upon enrolling in the plan. Thus, if a plan charges a lower Part B premium than the standard FFS premium, it is not displayed in the initial comparison of plans. Figure 2 displays an example of an initial page of search results on the Medicare Plan Finder. The initial plan listed is traditional FFS Medicare, and the subsequent plans are two MA plans (additional plans not shown). In order to view the Part B premium amount the consumer must click on the name of a plan to get to a page with more detailed information about the plan, scroll down to the section labeled "monthly premiums" and view the Part B premium listed in that section. Furthermore, the page with detailed plan information displays the net Part B premium (i.e. the original Part B premium minus any buy-down by the plan) so unless the enrollee recalls the original Part B premium it may not even be clear that the Part B premium available under the plan is lower than the original Part B premium, particularly if the reduction is only a few dollars. The second way beneficiaries enroll in a plan is through an agent or broker. We have less information on the way the Part B premium is communicated to consumers in that setting, as it will vary by agent or broker. However, in promotional materials released by the insurers themselves, a plan's monthly premium is also displayed as the Parts C and D premium only. Given these circumstances, consumers are likely to view all plans with a "zero" premium as having the same price, regardless of the Part B premium amount. A final reason that the Part B premium may not be salient to consumers is that most beneficiaries have their Part B premium automatically deducted from their Social Security check. Many consumers may not even connect the automatic deduction from their Social Security check with their MA plan, particularly because it is not emphasized during the enrollment process.

The implication is that if an MA plan premium is less than or equal to the premium the consumer would pay under FFS Medicare, the premium is communicated to consumers as $\$ 0$. Labeling this level of premium as "zero" creates the mistaken impression that 1) plans with a zero premium are free, and 2) that a zero premium plan is the cheapest possible plan. We explore the implications of these features for determining equilibrium premiums and benefits, and for the pass through of government subsidies below.

\subsection{Previous Literature}

A large prior literature has studied the behavior of private plans in Medicare since their introduction

in the 1980s. Past research has found that enrollment, plan availability, and plan generosity have been highly responsive to changes in payment rates (McGuire et al., 2011). There is also substantial 
evidence that prior to risk-adjustment there was advantageous selection into this market, with healthier beneficiaries choosing private plans and sicker beneficiaries preferring to stay in FFS Medicare (Medicare Payment Advisory Commission (2000), Morgan et al. (1997)). However, recent evidence indicates that selection is becoming much less of a problem under the new risk adjustment methodology (McWilliams et al., 2012; Newhouse et al., 2012).

Much of the prior literature studies the pre-2006 period before the current payment system based on the bidding and rebate mechanism began. Song et al. $(2012,2013)$ provide the first evidence of how plan bids respond to changes in benchmark payment rates under the current payment system. They estimate market-level models and find that a $\$ 1$ increase in the benchmark is associated with a $\$ 0.49$ increase in HMO plan bids. This indicates that plans have some flexibility in selecting their bid, despite the restriction that the bid equal an allowed mark-up of the plan's cost of providing the standard benefit package. Song et al. $(2012,2013)$ interpret these estimates as meaning that $\$ .49$ of every $\$ 1$ increase in benchmark payments is captured by plans as higher profits, and infer that the remaining portion that results in higher rebate payments is passed on to consumers in the form of more generous benefits or lower premiums. This paper furthers their analysis by directly estimating the extent to which higher benchmark payments are passed onto consumers in the form of lower premiums or more generous benefit packages. To our knowledge, no published work examines how plan premiums and benefits respond to benchmark payment changes within the current payment regime based on bids and rebates. Concurrent work by Duggan et al. (2014) estimates how benchmark payment rates affect premiums and benefit generosity as part of an analysis of the division of surplus between consumers and private insurers in the MA market under the current payment regime. Using a different source of variation in benchmark payment rates, they estimate effects on premiums and benefit generosity similar to what we find in this paper. However, they find that bids are more responsive to benchmark changes (i.e. rebates are less responsive) compared to the estimates in Song et al. $(2012,2013)$ and this paper. Interestingly, they also find that higher benchmarks do not have a measurable effect on plan quality and may cause insurers to spend more on advertising.

Our focus on the response of benefit generosity to payment rates in the MA market is closely related to the work of Pizer et al. (2003) on Medicare+Choice, the previous incarnation of Medicare Advantage. The Medicare+Choice market differed from the current MA market in that all plans were paid the same benchmark payment rate for a given enrollee in a given county. Plans did not bid or receive rebates from CMS, so the benchmark functioned as a simple cost subsidy. Additionally, plans were not allowed to charge a premium lower than that of FFS Medicare by buying down the Part B premium as in the current MA market. Pizer et al. (2003) argued that the lower bound on premiums prevented some plans from selecting an interior optimum of the premium and benefit combination that maximizes consumer utility. They found that in the Medicare+Choice market 
benefit generosity responded more to payment rate changes in "zero" premium plans (i.e. where the premium was equal to the FFS Medicare Part B premium) relative to non-zero premium plans (where the premium exceeded the Part B premium). They interpret this as evidence of inefficiently high benefits in zero-premium plans based on the assumption that zero-premium plans would have chosen the lower benefit increases (and premium decreases) of non-zero premium plans if they had been able to decrease premiums further. ${ }^{11}$

Based on their findings Pizer et al. (2003) argued that removing the lower bound on premiums by allowing plans to offer premium rebates would allow plans that were constrained under the old system to select an unconstrained optimal combination of premium and benefit generosity, with premiums below the FFS Medicare Part B premium and less generous benefits. This is similar to the policy now in place where plans have the option of buying down the Part B premium, as described above. However, we still observe over half of consumers enrolled in plans offering a premium equal to exactly the FFS Part B Premium and only $5 \%$ of consumers enrolled in plans with premiums less than FFS Medicare through Part B premium buy downs. This suggests that some real or perceived constraint still exists that causes a non-smooth demand response, which we explore in this paper.

\section{Theoretical Predictions}

We begin by deriving predictions from two simple models of plan premium and benefit setting that will be useful in interpreting our empirical results. In the first, consumers observe and respond to the "real price" of a plan, whereas in the second, the real price is obscured for the institutional reasons described above.

\subsection{Basic Model with Observed Premium}

Let consumer demand for plan $j$ be a general function of the additional benefit generosity of the plan and its premium, $s_{j}\left(p_{j}, b_{j}\right)$ and denote the profit function of plan $j$ as

$$
\pi_{j}=[\underbrace{\text { bid }_{j}+p_{j}+.75\left(\text { bench }_{j}-\text { bid }_{j}\right)}_{\text {revenue }} \underbrace{-b_{j}-P t A B_{j}}_{\text {cost }}] s_{j}\left(b_{j}, p_{j}\right)-F C_{j}
$$

\footnotetext{
${ }^{11}$ If CMS was able to enforce the requirement that additional payments be allocated toward lower premiums or more generous benefits this result is mechanically true due to the zero lower bound. Of course, non-zero premium plans may not be a good counterfactual for zero premium plans since the consumers that select into the two different types of plans likely have different preferences over premiums and benefits. Despite these issues their main argument, that the lower bound on premiums prevents some plans from selecting an interior optimum of the premium and benefit combination that maximizes consumer utility, is sound.
} 
where $b_{i d}$ denotes the plan's bid, bench ${ }_{j}$ denotes the plan's benchmark payment rate, $P t A B_{j}$ denotes plan $j$ 's cost of covering the standard level of benefits provided under Parts A and B of traditional FFS Medicare (hereafter referred to as standard benefits), $F C_{j}$ denotes the plan's fixed costs, $p_{j}$ denotes the premium, and $b_{j}$ represents the level of additional benefits (above the required standard benefit package) and is measured in dollars spent by plan $j$. In this notation, $p_{j}$ denotes the net premium revenue received by the plan, which equals the sum of the Parts $\mathrm{C}$ and $\mathrm{D}$ premium minus any Part B premium buy down. A positive $p_{j}$ indicates the plan sets the Part $\mathrm{C}$ and $\mathrm{D}$ premium equal to $p_{j}$ and does not buy down the Part B premium, while a negative $p_{j}$ indicates the plan sets a zero Part $\mathrm{C}$ and $\mathrm{D}$ premium and buys down the Part B premium by $p_{j}$. The term in brackets is the plan's per-enrollee profit. For each enrollee the plan receives its bid, rebate payment, and net premium as revenue and incurs the cost of providing the standard benefit package plus the cost of providing any additional benefits.

Medicare Program rules specify that benefits above the generosity of the standard benefit package, $b_{j}$, must equal the sum of the plan's net premium revenue and the rebate payment.

$$
b_{j}=p_{j}+\underbrace{.75\left(\text { bench }_{j}-\text { bid }_{j}\right)}_{\text {rebate }}
$$

This constraint makes it clear that the entire rebate payment must go toward either additional benefits or lower premiums. When the rebate increases, either $b_{j}$ must increase or $p_{j}$ must decrease (or some combination), for the equation to balance. Note that due to this constraint the plan's unit profit is determined solely by its bid. This can be seen readily by using the constraint to substitute out for $p_{j}$ in the profit function

$$
\pi_{j}=\left[\text { bid }_{j}-\operatorname{PtAB} B_{j}\right] s_{j}\left(b_{j}, b_{j}-.75\left(\text { bench }_{j}-\text { bid }_{j}\right)\right)-F C_{j}
$$

The plan chooses the size of the rebate, and thus the amount of the benchmark to pass onto consumers, through its choice of bid. In other words, MA plans exercise any market power by marking up their bid, rather than the premium, over costs (Song et al., 2013).

In order to simplify expressions and focus on the response of premiums and benefit generosity, the following models take that bid (and hence rebate) choice as given and ask how a plan will adjust its premium and benefit generosity for a given bid/rebate response. Incorporating the bid as an additional endogenous variable complicates some of the expressions, but does not change the model's implications for equilibrium benefit generosity or the comparative statics of premiums and benefits with respect to the rebate. ${ }^{12}$ In the empirical work, we will estimate the rebate/bid

\footnotetext{
${ }^{12}$ This is because given the choice of mark-up, the plan maximizes profits by choosing its premium and benefit generosity to maximize demand, so $p_{j}$ and $b_{j}$ are only affected by the plan's bid choice via its effect on the size of the rebate payment.
} 
response to the benchmark directly, since it affects the magnitude of the predicted premium and benefit response to a change in benchmark.

For a given bid, the plan chooses a premium and benefit generosity to maximize profits. Given that additional benefits and the premium are related by the rebate constraint, we simplify the plan's choice to be over a single variable, which yields the profit maximizing choices of the premium and benefit generosity as

$$
\begin{gathered}
b_{j}^{*}=\frac{\text { rebate }_{j}}{1+\varepsilon_{p} / \varepsilon_{b}} \\
p_{j}^{*}=\frac{\text { rebate }_{j}}{1+\varepsilon_{p} / \varepsilon_{b}}-\text { rebate }_{j}
\end{gathered}
$$

Thus the comparative statics of equilibrium premium and benefit generosity with respect to the benchmark and the rebate are a function of the relative demand elasticities with respect to premiums and benefits, $\varepsilon_{p}$ and $\varepsilon_{b}$.

$$
\begin{gathered}
\frac{\partial b_{j}}{\text { bbench }_{j}}=\frac{1}{1+\varepsilon_{p} / \varepsilon_{b}} \frac{\text { drebate }_{j}}{\text { dbench }_{j}} \\
\frac{\partial p_{j}}{\text { bench }_{j}}=\left\{\frac{1}{1+\varepsilon_{p} / \varepsilon_{b}}-1\right\} \frac{\text { drebate }_{j}}{\text { dbench }_{j}}
\end{gathered}
$$

The comparative statics with respect to the rebate give the predicted share of each additional rebate dollar to be allocated between benefits and premiums.

$$
\begin{gathered}
\frac{\partial b_{j}}{\text { drebate }_{j}}=\frac{1}{1+\varepsilon_{p} / \varepsilon_{b}} \\
\frac{\partial p_{j}}{\text { drebate }_{j}}=\frac{1}{1+\varepsilon_{p} / \varepsilon_{b}}-1
\end{gathered}
$$

This general set-up does not yield any predictions for the response of premiums and benefits to changes in the benchmark payment rate without knowledge of the relative size of the elasticities. We can generate clear predictions by placing more structure on the consumer demand and utility functions. Consider a market where homogeneous consumers have quasi-linear utility over MA plan benefits. We denote utility for plan $j$ as

$$
u_{j}=v\left(b_{j}\right)-p_{j}
$$

where consumers are assumed to have concave utility over plan benefit generosity, $v^{\prime}>0$ and 
$v^{\prime \prime}<0$. The profit function is then

$$
\pi_{j}=\left[b_{j}+p_{j}+.75\left(\text { bench }_{j}-b i d_{j}\right)-b_{j}-P t A B_{j}\right] s_{j}\left(v\left(b_{j}\right)-p_{j}\right)-F C_{j}
$$

where the demand function for plan $j, s_{j}\left(u_{j}\right)$, is now assumed to be an increasing function of consumer utility for plan $j, s^{\prime}>0$.

Maximizing over benefit generosity yields the equilibrium condition

$$
v^{\prime}\left(b^{*}\right)=1
$$

which implicitly defines the plan's profit maximizing benefit generosity. Using the rebate constraint, the optimal premium is then given by

$$
p_{j}^{*}=b_{j}^{*}-\text { rebate }_{j}
$$

The first condition states that the plan will set benefit generosity such that the marginal utility of benefits is equal to the marginal utility of a dollar to the consumer (which is also equal to the marginal cost of an additional unit of benefits, given our normalization). This model implies that benefits are always set at the socially optimal level, regardless of the benchmark payment rate, because consumers are always willing to pay an additional dollar in premiums for benefits they value at more than a dollar. At $b_{j}>b_{j}^{*}$ consumers would always prefer to pay a dollar less in premiums than have a benefits package that is a dollar more generous. The second condition indicates that the premium will then equal the cost of providing the optimal benefit generosity minus the rebate payment, the portion of the government subsidy the plan passes through to consumers.

From these two conditions the model's predictions of the response of benefits and premiums to changes in the benchmark payment rate easily follow as

$$
\frac{\partial b_{j}}{\text { bench }_{j}}=0
$$

and

$$
\frac{\partial p_{j}}{\text { bbench }_{j}}=-\frac{\text { drebate }_{j}}{\text { dbench }_{j}}
$$

These yield two clear testable predictions. First, plans will allocate the entire increase in the rebate payment following a benchmark payment increase toward lowering premiums. Second, changes to the benchmark payment rate will not affect the equilibrium level of benefits. These predictions serve as a useful benchmark for comparing the predictions of the next model, which incorporates the lack of premium transparency described earlier. Note that this model does not yield any testable 
predictions of the level of premiums or benefits. Based on consumer preferences (the $v(\cdot)$ function) benefit generosity and the corresponding premium might be very high or very low. The model predicts that once the plan has optimized over the level of benefit generosity and corresponding premium, future changes in the benchmark should only affect premiums.

\subsection{Lack of Premium Transparency and a Kinked Demand Curve}

The previous model implicitly assumed that both premium and benefit information are fully transparent to consumers when they select a plan. However, we have argued that the choice environment makes it difficult for consumers to observe premium reductions below the FFS Part B premium. Given this lack of premium transparency and the large degree of clustering of plans with premiums equal to the FFS Part B premium, we hypothesize that consumer demand is not sensitive to premiums that are less than or equal to the FFS Part B premium. This type of demand response can be represented with a kinked demand curve where plans face a downward sloping demand curve until the Parts $\mathrm{C}$ and D premiums reach zero and the total premium equals the FFS Part B premium, after which demand becomes much less responsive.

To formalize how a kinked demand curve affects the plan's optimal choice of benefits we replace $u_{j}=v\left(b_{j}\right)-p_{j}$ with the "decision utility" $u_{j}=v\left(b_{j}\right)-p_{j} 1\left\{p_{j}>0\right\}-\alpha p_{j} 1\left\{p_{j} \leq 0\right\}$, where $0 \leq \alpha<1$. This captures that consumers fully respond to premiums above the kink, but less than fully respond to premiums below the kink, or even don't respond at all if $\alpha=0$. We now write the plan's problem as

$$
\max _{p_{j}}\left[b i d_{j}-P t A B_{j}\right] s_{j}\left(v\left(.75\left(\text { bench }_{j}-b i d_{j}\right)+p_{j}\right)-p_{j} 1\left\{p_{j}>0\right\}-\alpha p_{j} 1\left\{p_{j} \leq 0\right\}\right)-F C_{j}
$$

where we've now substituted out for $b_{j}$ using the constraint. There are two potential FOCs for $p_{j}$, depending on whether $p_{j}>0$

$$
\begin{aligned}
& {\left[b i d_{j}-P t A B_{j}\right] s_{j}^{\prime} \cdot\left[v^{\prime}-1\right]=0} \\
& {\left[b i d_{j}-P t A B_{j}\right] s_{j}^{\prime} \cdot\left[v^{\prime}-\alpha\right]=0}
\end{aligned}
$$

When $p_{j}^{*}>0$, the equilibrium is the same as in the non-kink case, with $v^{\prime}\left(b_{j}^{*}\right)=1$ and $p_{j}^{*}=$ $b_{j}^{*}-$ rebate $_{j}$. If not, the plan increases $b_{j}$ past the efficient $b_{j}^{*}$, up until the point where $v^{\prime}\left(b_{j}\right)=\alpha$. For $\alpha$ sufficiently close to zero, as we expect, there will be no interior solution allowing the FOC to hold. The corner solution will be to drive the FOC as close to zero as possible by setting $p_{j}=0$ and allocating the entire rebate payment toward benefits, $b_{j}=$ rebate $_{j}$. In that case,

$$
\frac{\partial b_{j}}{\text { bench }_{j}}=\frac{\text { drebate }_{j}}{\text { dbench }_{j}}
$$


indicating a prediction that all additional rebate dollars stemming from a benchmark payment increase will be allocated to making plans more generous rather than less expensive. Intuitively, plans have no incentive to reduce the premium further because doing so does not increase quantity demanded (or has a very small effect) and comes at the opportunity cost of allocating the rebate dollars toward higher benefits, which at least have some effect on demand.

The implications of the kinked demand response for equilibrium premiums and benefits can best be seen by plotting the corresponding indifference curves, $\theta(b ; u)$, representing the amount consumers are willing to pay for each level of benefits at a given utility level. ${ }^{13}$ Figure 3 depicts these functions for three different utility levels, where consumers are indifferent between each point on a given curve. For each utility level, the function is concave in $b$ as long as the premium remains greater than or equal to the FFS Medicare Part B premium. At the FFS Part B premium, the curve becomes vertical reflecting the fact that consumers are not willing to trade-off any amount of benefits for a premium reductions below that level. The dotted lines represent what the function would be if premiums were fully transparent to consumers.

Figure 3 also plots the identity that relates the plan premium, benefit generosity, and rebate payment. When utility is quasi-linear in premiums and plan benefits, the case discussed above, in the absence of the kink the equilibrium benefit generosity occurs where the marginal rate of substitution between benefits and money is equal to the marginal cost of benefits, or where the indifference curve is tangent to the identity. When the rebate is equal to rebate ${ }^{\prime}$, the equilibrium is unconstrained by the kink and benefits are at the efficient $b^{*}$. However when the rebate increases to rebate $e^{\prime \prime \prime}$, equality between the kinked indifference curve and the identity occurs at the kink of $\theta\left(b ; u_{2}\right)$ where $b>b^{*}$. Were the premium fully transparent to consumers, equilibrium would occur at the point of tangency between the identity and the non-kinked indifference curve, $\theta\left(b ; u_{3}\right)$, at $b^{*}$ yielding a higher consumer utility level, $u_{3}>u_{2}$. The vertical distance between the identity at

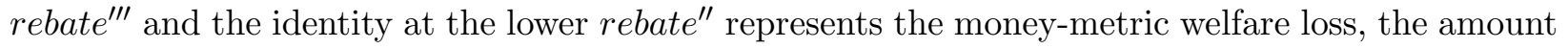
of money that could have been saved to achieve the same level of utility.

The graph makes clear that there will be a range of rebate amounts for which plans will price exactly at the kink, resulting in a lack of response of premiums to local changes in benchmark payment rates. The kink can also explain the cross-sectional bunching of plans at the "zero" premium level. Any plan composed of consumers of a type whose un-kinked indifference curve is tangent to the identity below the FFS Part B premium will choose a premium equal to the FFS Part B premium. To emphasize this phenomenon, we've depicted extreme versions of the kinked indifference curves, where consumers are not willing to trade-off any amount of benefits for a premium below the Part $\mathrm{B}$ premium $(\alpha=0)$. More generally, any set of indifference curves that became steeper at the kink would also result in bunching of plans at the "zero" premium level and a welfare loss from

\footnotetext{
${ }^{13}$ These may also be referred to as expenditure functions, as in Rosen (1974).
} 
inefficiently high benefits.

Our Figure 3 parallels Figure 1 in Pizer et al. (2003), who studied plan premiums and benefits under Medicare+Choice. Whereas in Pizer et al. (2003) the plan is constrained not to charge a premium below the FFS Part B premium, in our model the kinked demand response induces plans to choose a premium equal to the FFS Part B premium. The result is the same, leading to an equilibrium where welfare could be improved by lowering benefits and premiums.

We will rely on the insights of both of these models in interpreting our empirical results. The kinked demand model explains why we expect to see plans passing on higher benchmarks through more generous benefits when plans are within the range where demand is not responsive to lower premiums. The key insight from the simple, observed premium model is that profit-maximizing plans offer any benefits that consumers value at or above the plan's cost of providing those benefits, regardless of the subsidy level. If this is true then incremental changes in benefits caused by changes to the subsidy level must not be valued by consumers at cost. The kinked demand curve creates an incentive for plans to pass on higher subsidies through more generous benefits, even if those benefits are not valued by consumers at their cost, because doing so is the only way to affect demand.

\section{Empirical Methodology and Data}

\subsection{Identification Strategy}

Our research design exploits changes in benchmark payment rates within plans over time. Our approach is similar to the identification strategy employed by Song et al. (2012), with the main difference being that they estimate market-level models while we estimate plan-level models (i.e. they utilize variation within markets over time). For this source of variation to identify the effect of interest, it must be the case that changes in benchmark payment rates are uncorrelated with changes in other unobserved factors affecting changes in plan rebates, premiums, and benefits. CMS updates benchmark payment rates annually, and the type of update depends on whether the year is a rebasing or non-rebasing year. In non-rebasing years, all county benchmark payment rates receive the same percentage update. In rebasing years, county benchmarks receive the maximum update possible under a number of potential politically motivated update mechanisms (including floor payments to rural and urban counties, increases based on national trends, increases based on historical payment rates, and increases based on lagged estimates of county per-capita spending under FFS Medicare). This leads to a "ratcheting up" effect because payments can only increase under this system, never decrease. As a result, benchmark changes in rebasing years are based on a hierarchy of administrative update rules largely unrelated to changes in contemporaneous costs (Biles et al., 2009). The assumption that changes in payment rates are orthogonal to changes in costs 
and other determinants of plan profitability has been used frequently in the prior literature (Frakt et al. (2012), Song et al. (2012), Chernew et al. (2008)). To further investigate this assumption, we plotted changes in plan benchmarks against changes in the best available measure of plan costs, the realized per-capita spending by FFS Medicare in the plan's service area, in our analysis sample (described in more detail in the next section). ${ }^{14}$ The FFS spending data capture market level trends in medical care utilization, including adoption of new technologies. Since one potential update mechanism is based on lagged measures of this variable, this is the exact mechanism by which we might be concerned that benchmark changes are correlated with changes in plan costs. We do not find a strong or systematic relationship between changes in benchmarks and changes in FFS spending in our data, as shown in Figure A.1, giving us confidence that benchmark changes are uncorrelated with changes in unobserved costs.

Using variation within plans over time controls for unobservable, time-invariant plan characteristics that may be correlated with benchmark payment rates, including time-invariant characteristics of the plan's market, known as its service area. An approach relying on changes in benchmark payments over time, rather than cross-sectional variation in benchmarks across plans, is preferable because in the cross-section areas with higher benchmarks are also different along other unobservable dimensions that also affect plan rebates, premiums, and benefits. This is because benchmark levels are partly based on historical differences in per-capita FFS spending levels such that, for example, counties with high benchmark levels may be areas where providers tend to practice an intensive style of care. In contrast, changes in benchmarks over time are unlikely to be problematic for reasons described in the last paragraph.

We focus on benchmark payment changes that occurred between 2006-2007 and 2008-2009 for two main reasons. First, we want to restrict our analysis to before 2012, since beginning in 2012 benchmark payment changes are correlated with plan quality as measured by star level. This leaves 2006-2011 as potential study years (MA began in 2006). Of these years, 2007 and 2009 are the only payment rebasing years. Aggregated to the plan-year level, the mean plan benchmark change in our sample was $\$ 33.81$, with a standard deviation of $\$ 17.55$ (benchmarks are set on a per-member per-month basis, so the implied annual change is $\$ 405.72) .{ }^{15}$

To identify the marginal allocation of rebate dollars we focus on three outcome measures. First, we estimate the response of the plan rebate to changes in the benchmark to ascertain the additional rebate dollars to be allocated toward lower premiums and additional benefits. As described earlier, the plan receives a rebate payment from CMS equal to $75 \%$ of the difference between its bid and the benchmark, which it then must pass on to consumers through premiums or benefits. A

\footnotetext{
${ }^{14}$ The measure is standardized to an individual of average risk.

${ }^{15}$ These are the enrollment-weighted statistics. The unweighted mean and standard deviation are $\$ 32.43$ and $\$ 14.72$, respectively.
} 
plan therefore chooses the portion of the benchmark to pass on to consumers by adjusting its bid. The additional rebate dollars to be allocated toward premiums or benefits will be equal to $\Delta$ rebate $_{j}=.75\left(\Delta\right.$ bench $\left._{j}-\Delta b i d_{j}\right)$. If the plan does not adjust its bid following a benchmark increase, the rebate increases by $\$ 0.75$ for every $\$ 1$ increases in the benchmark. If the plan increases its bid by the full amount of the benchmark increase, then the rebate will not change.

We next estimate the response of the plan premium to changes in the benchmark. A response of plan premiums to benchmark payment changes can be interpreted as plans allocating additional rebate dollars toward premium reductions, since an exogenous change in the benchmark should only affect plan premiums via the effect on rebates. As plans are required to allocate the rebate towards either premiums or benefits, we interpret the change in benefits as the residual of the change in rebate minus the change in premiums. We attempt to estimate the change in benefits directly using a summary measure of benefits generosity, the projected out-of-pocket costs (OOPC) for each plan. As discussed below this is an imprecise measure of the true plan benefit generosity, so we will put more weight on the findings based on premiums, which are precisely measured.

\subsection{Econometric Specification}

Our econometric specification is

$$
y_{j t}=X_{j t}^{\prime} \beta+\gamma \text { bench }_{j t}+\delta_{t}+\psi_{j}+\varepsilon_{j t}
$$

where $y_{j t}$ is the rebate, premium, or benefit generosity of plan $j$ in year $t, X_{j t}$ is a vector of plan characteristics in year $t$, bench j $_{j t}$ is the plan benchmark in year $t, \delta_{t}$ is a vector of year dummies, and $\psi_{j}$ is a vector of plan fixed effects. We describe how we construct the plan benchmark from administratively set county benchmarks in the next section. To isolate variation between 20062007 and 2008-2009, we first difference the data and estimate our models on the 2007 and 2009 first differenced data.

$$
\Delta y_{j t}=\Delta X_{j t}^{\prime} \beta+\gamma \Delta \text { bench }_{j t}+\Delta \delta_{t}+\Delta \varepsilon_{j t}
$$

The identifying assumption is that, conditional on $\Delta X_{j t}$ and $\Delta \delta_{t}$, changes in the benchmark payment rates within plans are uncorrelated with the error. The coefficient of interest is $\gamma$, the impact of a $\$ 1$ change in benchmark payment rates on plan premiums and benefit generosity. We present results with several specifications of $X_{j t}$. The fixed effects specification already controls for time invariant plan characteristics and the time effect controls for changes that were common to all plans over time, so the reason for including additional controls in $X_{j t}$ is to account for time-variant plan (including market) characteristics that may be correlated with both benchmark payment changes and our outcomes of interest. 
The main time-varying factors of concern are changes in plan costs and market structure. As described above, the best available measure of MA plan costs is the realized FFS Medicare percapita expenditures in each county. Although we did not find a strong relationship between changes in FFS spending and changes in benchmarks, our preferred specification nevertheless includes this variable as the best available measure of plan costs. ${ }^{16}$ The results are very similar when we don't condition on contemporaneous FFS costs, giving us additional confidence that underlying changes in unobserved costs are uncorrelated with benchmark changes. Changes in market structure may be a concern if insurers tend to enter markets that receive higher benchmark payment increases, as earlier work has found. To address this concern we control for the number of insurers in the plan's market, as described in more detail in the next section. We also estimate specifications allowing for plan-type specific time trends for additional flexibility. Since our sample includes only two plan types, HMOs and PPOs, this consists of adding an interaction of a dummy for PPO and $\delta_{t}$. We weight all regressions by mean plan enrollment over the sample period and cluster standard errors at the plan level.

In interpreting our results, a few limitations should be kept in mind. First, since we measure plan responses occurring in the same year of the benchmark payment change these are short run estimates. Increases in benchmarks may have longer-term effects, including on insurer entry and the number of Medicare beneficiaries choosing MA, that could affect plan premiums and benefit generosity. Second, our analysis treats the plan as the profit maximizing unit. Since insurers typically have multiple plans in a given market, the insurer is more likely to be the profit maximizing unit. However, treating the plan as the unit of analysis makes the empirical work easier to interpret, since our outcomes of interest vary at the plan level. Finally, the range of benchmark variation in our study years was relatively modest. Plan responses could be quite different with more dramatic changes in benchmark levels.

\subsection{Data}

We use plan- and county-level data from the Center for Medicare and Medicaid Services (CMS) for plan years 2006-2009: data on plan bids and rebates comes from the plan payment files; data on enrollment comes from the plan enrollment files and Contract-Plan-State-County enrollment files; data on county-level benchmark payment rates and FFS costs come from the MA Ratebooks and the County FFS Expenditure data; data on plan premiums and benefit generosity comes from the Medicare Options Compare database. Our measure of benefit generosity is the projected

\footnotetext{
${ }^{16}$ To some extent plan costs may also respond to changes in benchmarks if, for example, providers are able to negotiate higher reimbursement rates following benchmark increases. We also note that it is possible that FFS costs could respond to changes in benchmark payment rates if increases in benchmarks change the pool of individuals choosing MA vs FFS Medicare.
} 
out-of-pocket spending an average enrollee would expect to spend in each plan. These are the outof-pocket cost (OOPC) estimates beneficiaries see on the official CMS website when they browse and compare plans. They are computed by applying each plan's benefits rules (covered services, cost sharing) to the actual utilization of a sample of FFS Medicare beneficiaries responding to the Medicare Current Beneficiary Study (MCBS). The OOPC data are an imperfect measure of benefit generosity because they are estimated off a sample of FFS beneficiaries, do not reflect the risk pool of the plan, and assume no demand side response to the plan's benefit measure. Additionally, since the sample of MCBS respondents used to compute the OOPC estimates changes from year to year, the change in the sample introduces additional noise when comparing changes in the OOPC over time. However, they are the best available measures of plan benefit generosity, and other papers in the literature have relied on the OOPC as a summary measure of benefit generosity (McWilliams et al., 2011; Dunn, 2010). Unfortunately, the OOPC data is not available for 2006 so we are limited to estimating models of benefit generosity on the 2008-2009 sample. We also harmonize plan identifiers over time using the CMS plan crosswalk files. ${ }^{17}$

Benchmark payment rates are set at the county level, but CMS bases payments on plan-specific benchmarks, derived as a (projected) enrollment weighted average of the benchmarks of the counties in the plan's service area. Since we do not have access to the plan-specific benchmark used in practice, we construct plan-level benchmarks using an ex-post enrollment weighted average of the benchmarks of the counties in the plan's service area. A plan may change its service area from year to year. Since the changes over time in a plan's service area and the relative enrollment across the counties in its service area are endogenous to changes in benchmark payment rates (plans may enter into or more aggressively market to counties that experience large payment rate increases), we use weights that are stable over time to aggregate county-level benchmarks to the plan level. ${ }^{18}$ In this way, we are only using variation in benchmark payment rates resulting from administrative changes. We aggregate county per-capita FFS expenditure data to the plan level using the same weights.

There are three main types of plans in the MA market: HMOs, PPOs, and private fee-for-service (PFFS) plans. We focus on findings from HMO and PPO plans, because PFFS plans had a

\footnotetext{
${ }^{17}$ The Medicare Options Compare database for each of the years under study was procured from CMS. The remaining files are publicly available and can be found at Centers for Medicare \& Medicaid Services (2008-2009a), Centers for Medicare \& Medicaid Services (2008-2009b), Centers for Medicare \& Medicaid Services (2008-2009c), Centers for Medicare \& Medicaid Services (2008-2009d), and Centers for Medicare \& Medicaid Services (2008-2009e).

${ }^{18}$ If $J_{i}$ is the set of all counties existing in plan $i$ 's service area in at least one year, then plan $i$ 's weight for county $j$ is

$$
w_{i j}=\sum_{t} \text { enroll }_{j t} / \sum_{j \in J_{i}} \sum_{t} \text { enroll }_{j t}
$$

where $\sum_{j \in J_{i}} w_{i j}=1 \forall i$. Because not every county in $J_{i}$ exists in a plan's service area in any given year (i.e. $\left.\left|J_{i t}\right| \leq\left|J_{i}\right|\right)$ the weights are rescaled to sum to one within each year.
} 
different cost structure from HMO and PPO plans during our study period. ${ }^{19}$ We also eliminate a few particular types of MA plans that only serve a restricted set of Medicare beneficiaries. We eliminate Special Needs Plans which serve beneficiaries with specialized health care needs including institutionalized beneficiaries and dual eligibles. We also exclude regional PPO plans (which are reimbursed under a different set of payment rules) and employer plans (which are only available to current or former employees of a particular firm). Since we only have rebate data for plans bidding below the benchmark, we restrict our sample to those plans. Since $97 \%$ of HMO and PPO plans bid below the benchmark in 2006-2009, this eliminates very few plans. $^{20}$

A general concern with fixed effects specifications on firm level data is dealing with the potential selection problem caused by firm entry and exit. In our case, we observe very little exit in our study period so our sample can be said to be representative of plans in the base years before the benchmark payment changes (2006 and 2008). However we do observe some plan entry, particularly between 2006-2007. This entry largely consists of PFFS plans and small HMO and PPO plans (see Tables A.1 to A.3 for further detail). Although PFFS plans are not included in our analysis sample they do compete with the HMO and PPO plans in our sample to at least some degree. The concern for our identification strategy would be if entry was correlated with changes in both the benchmark and our outcomes of interest. We address this concern in two ways. First, we note that our analysis sample is very similar on observables to the unrestricted sample (Tables 1 and A.4). Second, we control for entry in our models by including the number of insurers in the plan's market. ${ }^{21}$ Note that since we estimate first differences models this controls for changes in the number of insurers, i.e. insurer entry. Our final sample consists of 1,085 plans that existed in both 2006 and 2007 and 1,461 plans that existed in both 2008 and 2009.

Tables 1 and 2 present enrollment weighted and unweighted summary statistics of our sample. The plan benchmark, bid, rebate, premium, and out-of-pocket cost are all measured on a per-member per-month basis. The average plan has over 4,300 enrollees, but there is a large degree of variation in plan size, with a standard deviation of over 9,000 (not shown). Weighting by plan enrollment, the average plan per-enrollee monthly benchmark is $\$ 785.36$ in 2006 and $\$ 877.92$ in 2009 . The average plan bids substantially below the benchmark, yielding a plan per-enrollee monthly rebate payment of $\$ 84.52-\$ 110.45$ which plans pass onto consumers in the form of premium reductions or more generous benefits. As noted earlier, over $50 \%$ of plans set a premium at exactly the FFS Medicare Part B premium by setting the Parts C and D premium to zero and not buying down the Part B premium. The projected out-of-pocket costs (OOPC) measure indicates that the average

\footnotetext{
${ }^{19}$ During this period, PFFS plans were not required to establish provider networks. Instead, they were allowed to pay providers using the rates established under the Medicare Fee Schedule for FFS Medicare.

${ }^{20}$ We might be concerned if benchmark changes caused plans to switch from bidding above to below the benchmark, however there are no plans in our sample for which this is the case.

${ }^{21}$ This is constructed as an enrollment-weighted average of the number of insurers in each county of the plan's service area, aggregated from the county to the plan-level in the same way as the benchmark and FFS cost variables.
} 
plan enrollee in 2009 can expect to spend $\$ 118.82$ per month out-of-pocket for medical expenses (not including the premium).

\section{Empirical Results}

Table 3 presents the results of regressions of the plan rebate, the portion of the benchmark payment that plans return to consumers in the form of lower premiums or more generous benefits, on the benchmark payment rate. We present specifications with no control variables (column 1), controlling for FFS Medicare spending (column 2), adding a separate time trend for the type of plan (column 3), and adding a control for the number of insurers in the plan's market (column 4). The four specifications are quite similar, with coefficients of interest on the benchmark ranging from 0.385-0.394. These estimates indicate that for every $\$ 1$ increase in the benchmark payment rate the rebate increases by $\$ 0.39$, in the case of our preferred specification. For comparison, Song et al. (2012), using market-level fixed effects models of the bid on the benchmark, found a coefficient of 0.49 on the benchmark which implies a increase in the rebate of $\$ 0.38((1-.49) \times .75)$ for every $\$ 1$ increase in the benchmark. Our estimates are consistent with their finding that only a portion of additional benchmark payments are captured by consumers through higher rebates.

Our primary interest is how plans allocate these additional rebate dollars between premiums and benefit generosity. Table 4 presents the results of regressions of the total plan premium (i.e. the sum of the Parts B, C, and D premiums) on the benchmark payment rate, using the same four specifications as Table 3. Again we find similar coefficients in all specifications, ranging from 0.070 to -0.061 , none of which are statistically different from zero at the $10 \%$ level. Although not statistically significant, the preferred point estimate of -0.062 represents $16 \%$ of additional rebate payments. These results indicate that on average plans allocate close to zero additional rebate dollars towards lowering premiums. ${ }^{22}$

Finally, we present estimates of regressions of our proxy for plan benefit generosity, the projected enrollee out-of-pocket spending (OOPC) under the plan, on the benchmark payment rate. These are estimated on the 2008-2009 sample only, since OOPC data is not available for 2006. For reference, the coefficient estimates of interest for the rebate and premium models presented in column 4 of Tables 3 and 4 estimated on the same 2008-2009 sample are 0.409 and -0.004 respectively. As noted earlier, the OOPC data provide an imprecise measure of plan benefit generosity because the OOPC is computed by applying each plan's cost-sharing structure to the utilization history of a changing sample of FFS Medicare beneficiaries. Given the measurement error in our outcome variable, we expect the coefficients of interest to be biased towards zero and do not expect to

\footnotetext{
${ }^{22}$ The results from models defining the premium as only the Part $\mathrm{C}$ and $\mathrm{D}$ premiums are virtually identical, since very few plans actually buy down the Part B premium.
} 
estimate a coefficient equal to the full change in the rebate. Nevertheless, we expect to see some response of this measure since it is correlated with benefit generosity. Note that since the OOPC is the out-of-pocket spending of the enrollee, a lower OOPC indicates that a plan has a more generous benefit package. Thus a negative coefficient indicates that benefit generosity increases following a benchmark payment increase. As shown in Table 5, we estimate coefficients ranging from -0.159 to -0.141 , all but one of which are significant at the $10 \%$ level. Not surprisingly, the $95 \%$ confidence intervals are quite large, ranging from -0.316 to 0.034 in the case of column 4 . We interpret these findings as providing qualitative support for our conclusion that plans are responding to benchmark payment increases by allocating rebate dollars towards more generous benefits, but do not put much faith in the point estimates.

We prefer relying on the point estimates from the rebate and premium models, since those outcomes are precisely measured, and using those estimates to infer the change in benefit generosity using the MA program accounting rules. As plans are required to allocate the rebate towards either premiums or benefits (and provide actuarial documentation that they have done so), we can infer the change in benefit generosity to be the residual of the change in rebate minus the change in premiums. Specifically, since a $\$ 1$ increase in the benchmark causes a $\$ 0.39$ increase in the rebate and relatively little change in premium then the causal effect on plan benefit generosity must be the majority of the increase in the rebate, $\$ 0.39$. This implies that the average plan returns all, or nearly all, of additional rebate dollars stemming from higher benchmark payment rates in the form of more generous benefits.

Our approach of inferring the change in benefits as the residual of the change in rebate and change in premium contrasts with that of Duggan et al. (2014), who instead interpret the sum of the premium and benefit estimates as the total pass-through to consumers. ${ }^{23}$ While we agree that estimating the total pass-through directly from each component would be ideal, given that the benefits estimates are almost certainly biased toward zero we do not feel confident in doing so. We prefer using the change in rebate as the best available measure of the overall change in pass-through and relying on the rebate constraint to infer changes in benefits, as described above. While we acknowledge that insurers may not perfectly comply with the constraints, we argue that the incentive structure is such that it is not in the interest of the plan to choose a rebate amount they do not intend to pass through to consumers via premiums or benefits. Since a portion of the difference between the bid and the benchmark (25\% during our study period) is retained by Medicare, plans forfeit $\$ 0.25$ of potential revenue for each $\$ 1$ they bid below the benchmark. If insurers were not bound by the rebate constraint we identify and were able set premiums and benefits without regard to the rebate, the optimal strategy would be to bid at the benchmark to maximize the subsidy from Medicare. Insurers choose to bid below the benchmark so they are allowed to make their plans

\footnotetext{
${ }^{23}$ They also consider changes in plan quality as a potential pass-through channel, but find no effect.
} 
more generous without a commensurate increase in premiums. As the rebate constraint provides the only incentive for plans to bid below the benchmark, and we observe nearly all plans doing so, we conclude it must have bite. As such, we feel reasonably comfortable inferring the change in benefits using the constraint.

Given that our kinked demand theory has different predictions for plans with premiums at the kink compared to plans with premiums above the kink in the base year (i.e. plans with premiums at versus above the FFS Part B premium in 2006 or 2008), we test for a differential effect for plans at the kink versus above the kink. To do so, we add an interaction of the benchmark variable with an indicator for whether the plan charged a premium above the FFS Part B premium in the base year (labeled NONZERO in the tables because this translates to a non-zero Parts $\mathrm{C}$ and $\mathrm{D}$ premium). We expect a benchmark increase to cause a decrease in premiums for plans above the kink and no change in premium for plans at the kink. That is, we expect the main effect to be zero and the interaction term to be negative in a regression with the total premium as the outcome variable.

We first present estimates with the rebate as the outcome variable, since these provide estimates of the share of additional benchmark dollars returned to consumers for plans at and above the kink, in Table 6. Column 1 reproduces the specification in column 4 of Table 3, column 2 adds the interaction term, and column 3 presents a robustness check dropping plans with very large premium changes (more than $\$ 100$ in abolute value). The coefficients on the main effect are similar to those in Table 3, and the coefficients on the interaction terms are positive, although not statistically different from zero in column 3. This indicates that the average plan above the kink returned more of the additional benchmark payment increase to consumers than the average plan at the kink. Now turning to models with the premium as the outcome variable, shown in Table 7, the main effect remains statistically indistinguishable from zero and our estimates of the interaction term are negative and statistically significant, ranging from -0.451 to -0.625 depending on the specification. These estimates indicate that plans at the kink do not adjust premiums in response to benchmark increases, but plans above the kink do decrease premiums, as predicted by the kinked demand theory. Tables 8 and 9 break out the estimates by sample period. For the 2006-2007 sample, plans at the kink experienced a modest or no increase in the rebate and did not adjust their premiums in response to additional benchmark payments. Plans above the kink increased the rebate by $\$ 0.71$ more than plans at the kink for every $\$ 1$ increase in the benchmark (statistically indistinguishable from a full pass-through of $\$ 0.75$ ) and decreased premiums by $\$ 0.67$ more, statistically indistinguishable from the $\$ 0.71$ additional rebate increase. For the 2008-2009 sample, plans at the kink increased their rebates but did not increase premiums in response to benchmark payment increases as expected, however the estimates for plans above the kink are too noisy to draw any conclusions. This may be because there is much less variation in the data available for estimating the effect of benchmark changes for plans above the kink between 2008-2009. For 
plans above the kink, the standard deviation of the 2008-2009 change in the benchmark was only $\$ 1.92$ (mean of $\$ 27.62$ ), whereas for plans at the kink, the standard deviation of the change in the benchmark was $\$ 25.56$ (mean of $\$ 36.24$ ). The fact that plans with premiums above the FFS Part B premium experienced very similar increases in the benchmark between 2008 and 2009 makes it difficult to estimate a separate treatment effect for this subset of plans. Unfortunately, we don't have an explanation for the difference in the rebate response for plans at and above the kink for the two sample periods. We conclude that the empirical support for the kinked demand theory is strongest for the 2006-2007 sample, although the 2008-2009 sample provides some additional support and does not contradict the theory.

Unfortunately we can only directly test for a differential response by type of plan for benefits (OOPC) in the 2008-2009 sample, when there is little variation in the data for estimating the effect of benchmark changes for plans above the kink. For the OOPC regressions, we expect a negative main effect and a positive interaction term of roughly equal size as the main effect since plans above the kink should not be changing benefit generosity in response to higher benchmarks (recall that a positive interaction term means plans above the kink are reducing out-of-pocket costs less than plans at the kink, meaning they are increasing benefit generosity less). As shown in Table 10, the main effect, although negative as expected, is no longer significant and the interaction term is imprecisely estimated.

\section{Discussion}

We find that on average benefit generosity, but not premiums, responds to changes in the benchmark payment rate, but for plans with premiums above the FFS Part B premium the opposite is true. These results are predicted by the kinked demand theory, but not the frictionless model where consumers perfectly observe premiums. The kinked demand curve creates an incentive for plans to pass on higher subsidies through more generous benefits, even if those benefits are not valued by consumers at their cost, because doing so is the only way to affect demand. The frictionless model, although it abstracts from many important factors, highlights the observation that consumers should always be willing to pay for benefits that are valued above their cost, regardless of the subsidy level. If this is true then incremental changes in benefits caused by changes to the subsidy level must not be valued at cost, meaning consumer welfare would be increased by applying additional rebate dollars toward lower premiums rather than more generous benefits. Thus the problem identified by Pizer et al. (2003) in the former Medicare+Choice program, that many plans offered efficiently high benefits because the lower bound on plan premiums prevented them from further reducing premiums, remains a concern in the current Medicare Advantage market. The lack of transparency of the Part B premium creates an artificial lower bound for plan premiums below which the returns 
to the plan of lowering the premium are close to zero, and the only way for plans to influence demand is by changing benefits.

If, as we have argued, a lack of salience of a reduction in the Part B premium causes consumers to "irrationally" not respond to premium reductions below the FFS Part B premium, a natural intervention would be to change the way premium information is presented on the Medicare Plan Finder website and plan promotional materials. For example, on the website the Part B premium amount could be displayed side-by-side with the Parts $\mathrm{C}$ and D premium and other key plan characteristics on the main plan comparison page. Alternatively, the tool could list only the total premium amount (the sum of the Parts B, C, and D premiums). This would make the relevant total premium most easily comparable across plans. CMS could also require plan promotional materials and agents and brokers selling MA plans to quote the total premium to consumers, rather than just the Parts $\mathrm{C}$ and $\mathrm{D}$ premium. These interventions should be relatively inexpensive to implement and could lead to more premium competition in the MA market. An alternative intervention would be for Part B premium buy-downs to be returned directly to consumers via premium rebate checks for the amount of the buy-down, rather than decreasing the Part B premium that is deducted from the Social Security check. Of course, the efficiency gains from this more far-reaching intervention would have to be weighed against the administrative costs of implementation. ${ }^{24}$

We argue here that a lack of transparency causes consumers to under-respond to premium changes. In the market for stand-alone Medicare Part D plans, which does not suffer from the same premium transparency issues, Abaluck and Gruber (2011) find that consumers tend to over-respond to premiums relative to dimensions of financial generosity, leading to inefficient plan choices. If consumers in the MA market similarly under-value plan generosity, it's possible that these two sources of inefficiency may be at least partially offsetting. In that case, the welfare effects of increasing premium transparency are unclear.

Since this study focuses on an insurance market, readers may wonder whether our results are affected by heterogeneity in risk type and potential adverse or advantageous selection. Although MA plans appear to have been benefiting from at least some favorable risk selection over the period of our study (Newhouse and McGuire, 2014), selection-related incentives are unlikely to be behind our results. The basic services-premium selection model implies that plans will set premium and services too low in equilibrium attempting to attract the better risks (Rothschild and Stiglitz, 1976). The comparative statics of such a model (corresponding to our empirical work), however, are not generally signed, but depend on the joint distribution of preferences and risks in the population. Furthermore, risk adjustment of plan premiums in MA can counteract selection incentives (Glazer

\footnotetext{
${ }^{24}$ Eliminating auto-deduction of the Part B premium from Social Security checks entirely is an additional option that would serve to make the Part B premium more salient to consumers. However, the administrative costs of such an option would likely be large
} 
and McGuire, 2000). In sensitivity analyses, controlling for the plan's average enrollee risk score had no material effect on our results. In sum, while we cannot rule out selection as at least a partial explanation, we believe that the explanation we propose, that plans pass on higher subsidies by offering more generous benefits because demand does not respond to premium reductions below the Part B premium level, is simpler and more likely.

\section{Conclusion}

Given the size of the Medicare Advantage program, both in terms of expenditures and the number of enrollees, understanding how the level of government subsidies affects the premiums and benefit generosity of plans is an important policy question in and of itself. As a result of the Affordable Care Act, benchmark payment rates now vary by plan quality rating and future benchmark payments are scheduled to decline (Jacobson et al., 2011). In addition to these changes, policy makers continue to discuss further changes to MA payments as a means to preserve Medicare's fiscal stability and bring costs in the MA market more in line with costs in FFS Medicare. Our estimates indicate that nearly all of the marginal subsidy dollars that are passed onto consumers via the rebate go toward making plans more generous, rather than reducing premiums. These findings suggest that plans will respond to future benchmark payment changes primarily by adjusting benefit generosity rather than premiums, at least for plans pricing at the kink.

We presented evidence that a kink in the demand curve at the FFS Part B premium level is an important feature of this market and argued that a lack of premium transparency below this level can explain our empirical results. To the extent that some of the additional benefits resulting from increases in government subsidies are inefficiently high, as we have argued, increasing premium transparency would improve consumer welfare in this market at no additional cost to the government. We discussed several simple policy interventions that should make the total premium, in particular premiums below the FFS Medicare premium achieved via a "buy down" of the Part B premium, more transparent and salient to consumers. Even if these interventions induce only small changes in premiums and benefits, given the size of the MA market even modest efficiency gains on a per person basis could produce sizable gains in aggregate. 
Figure 1: Weighted Distribution of Total Plan Premiums in 2008

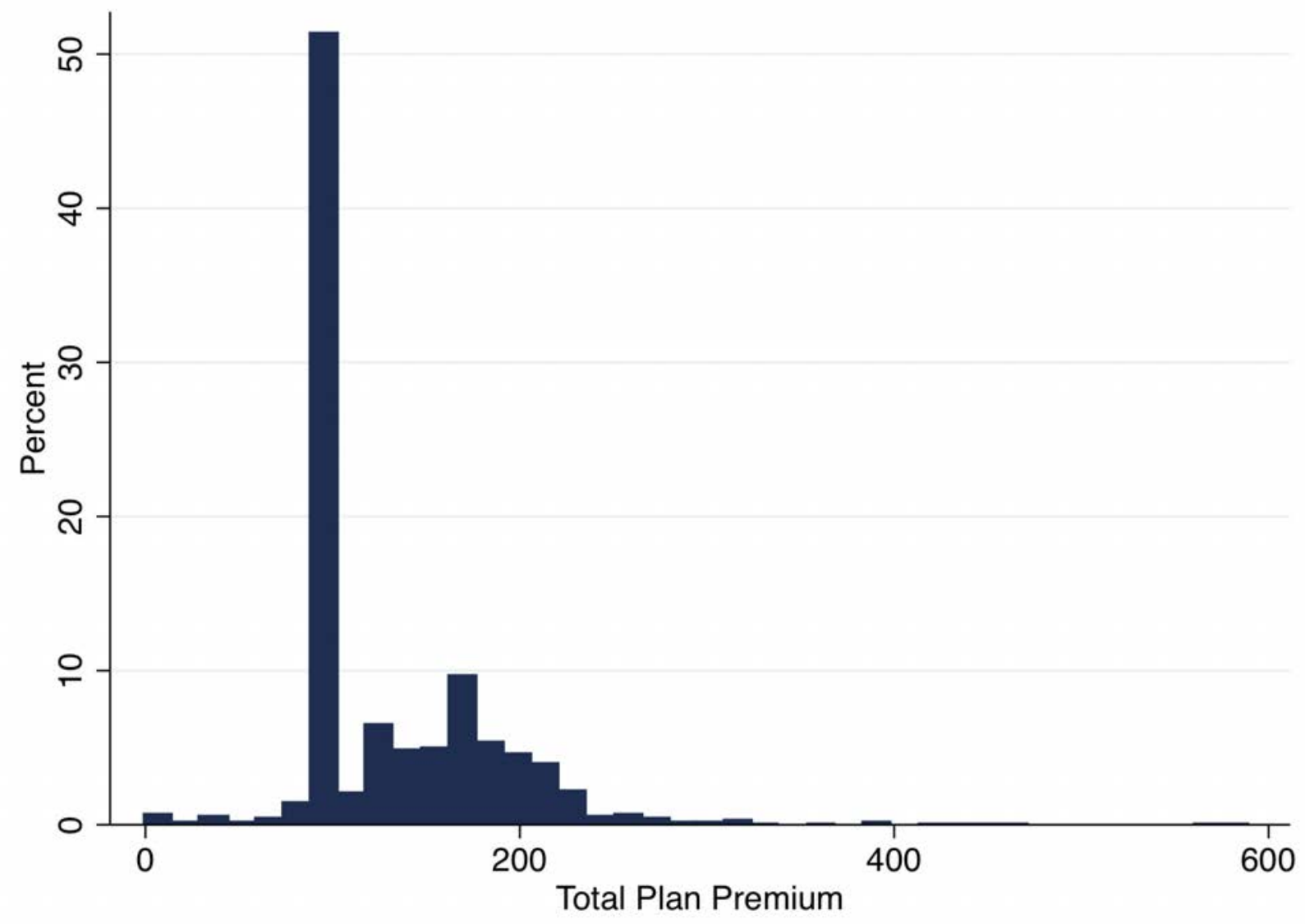

Source: 2008 Medicare Options Compare database. Weighted by plan enrollment. The total plan premium is defined as the sum of the Parts B, C, and D plan premiums. See text for details. 
Figure 2: Example of initial page of search results on Medicare Plan Finder website

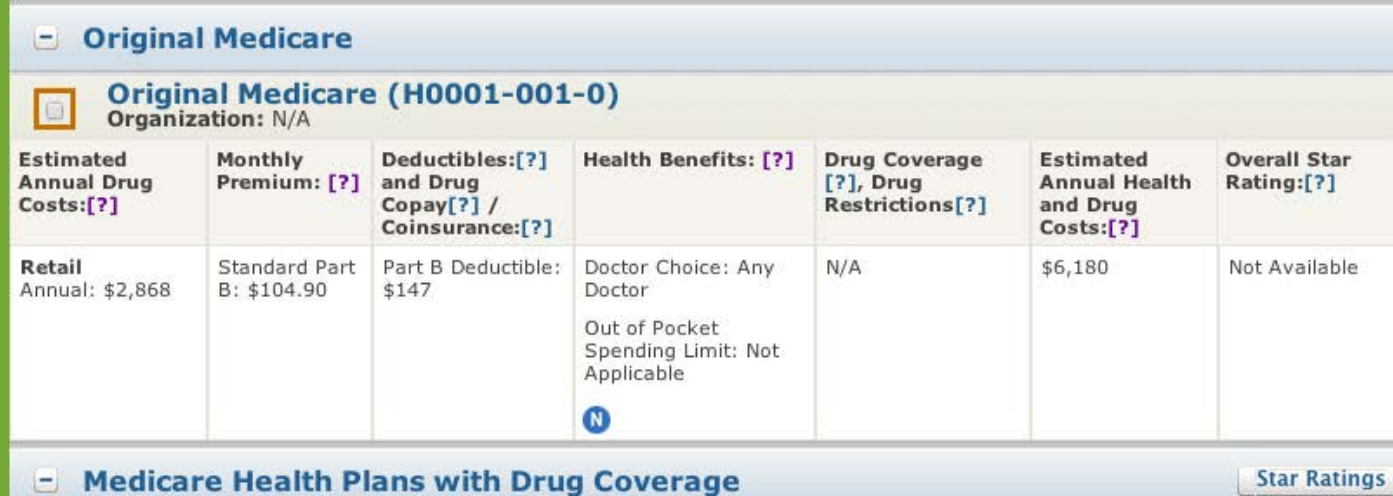

There are 16 plans in $\mathbf{0 2 1 4 3}$ that match your preferences. View 10 View 20 View 50

\section{Compare Plans 3}

Sort Results by Lowest Estimated Annual Health and Drug Cost $\quad$ Sort

Fallon Senior Plan Saver Enhanced RX (HMO) (H9001-030-2)

\section{Organization: Fallon Senior Plan or NaviCare}

\begin{tabular}{|c|c|c|c|c|c|c|c|}
\hline $\begin{array}{l}\text { Estimated } \\
\text { Annual Drug } \\
\text { Costs:[?] }\end{array}$ & $\begin{array}{l}\text { Monthly } \\
\text { Premium: [?] }\end{array}$ & $\begin{array}{l}\text { Deductibles [?] } \\
\text { and Drug } \\
\text { Copay[?] / } \\
\text { Coinsurance:[?] }\end{array}$ & $\begin{array}{l}\text { Health } \\
\text { Benefits: [?] }\end{array}$ & $\begin{array}{l}\text { Drug Coverage [?], } \\
\text { Drug } \\
\text { Restrictions [?] and } \\
\text { Other Programs: }\end{array}$ & $\begin{array}{l}\text { Estimated } \\
\text { Annual } \\
\text { Health and } \\
\text { Drug } \\
\text { Costs:[?] }\end{array}$ & $\begin{array}{l}\text { Overall Star } \\
\text { Rating:[?] }\end{array}$ & \\
\hline $\begin{array}{l}\text { Retail } \\
\text { Annual: } \$ 1,198\end{array}$ & $\begin{array}{l}\$ 37.00 \\
\text { Drug: } \$ 14.80 \\
\text { Health: } \$ 22.20\end{array}$ & $\begin{array}{l}\text { Annual Drug } \\
\text { Deductible: } \$ 0 \\
\text { Health Plan } \\
\text { Deductible: } \$ 0 \\
\text { Drug Copay/ } \\
\text { Coinsurance: } \$ 1 \text { - } \\
\$ 76,33 \%\end{array}$ & $\begin{array}{l}\text { Doctor Choice: } \\
\text { Plan Doctors } \\
\text { Only } \\
\text { Out of Pocket } \\
\text { Spending Limit: } \\
\$ 6,700 \text { In- } \\
\text { Network } \\
\text { D V } \mathbf{~}\end{array}$ & $\begin{array}{l}\text { All Your Drugs on } \\
\text { Formulary: No } \\
\text { Drug Restrictions: } \\
\text { No } \\
\text { No Additional Gap } \\
\text { Coverage } \\
\text { Lower Your Drug } \\
\text { Costs } \\
\text { MTM Program [?]: } \\
\text { Yes }\end{array}$ & $\$ 3,910$ & $\begin{array}{l}\pi k \pi k 7 \\
4.5 \text { out of } 5 \\
\text { stars }\end{array}$ & Enroll \\
\hline \multicolumn{8}{|c|}{$\begin{array}{l}\text { Tufts Medicare Preferred HMO Saver Rx (HMO) (H2256-028-0) } \\
\text { Organization: Tufts Health Plan or Tufts Medicare Preferred }\end{array}$} \\
\hline $\begin{array}{l}\text { Estimated } \\
\text { Annual Drug } \\
\text { Costs:[?] }\end{array}$ & $\begin{array}{l}\text { Monthly } \\
\text { Premium: [?] }\end{array}$ & $\begin{array}{l}\text { Deductibles [?] } \\
\text { and Drug } \\
\text { Copay[?] / } \\
\text { Coinsurance:[?] }\end{array}$ & $\begin{array}{l}\text { Health } \\
\text { Benefits: [?] }\end{array}$ & $\begin{array}{l}\text { Drug Coverage [?], } \\
\text { Drug } \\
\text { Restrictions [?] and } \\
\text { Other Programs: }\end{array}$ & $\begin{array}{l}\text { Estimated } \\
\text { Annual } \\
\text { Health and } \\
\text { Drug } \\
\text { Costs:[?] }\end{array}$ & $\begin{array}{l}\text { Overall Star } \\
\text { Rating:[?] }\end{array}$ & \\
\hline $\begin{array}{l}\text { Retail } \\
\text { Annual: } \$ 1,152\end{array}$ & $\begin{array}{l}\$ 0.00 \\
\text { Drug: } \$ 0.00 \\
\text { Health: } \$ 0.00\end{array}$ & $\begin{array}{l}\text { Annual Drug } \\
\text { Deductible: } \$ 0 \\
\text { Health Plan } \\
\text { Deductible: } \$ 0 \\
\text { Drug Copay/ } \\
\text { Coinsurance: } \$ 5- \\
\$ 95,33 \%\end{array}$ & $\begin{array}{l}\text { Doctor Choice: } \\
\text { Plan Doctors } \\
\text { Only } \\
\text { Out of Pocket } \\
\text { Spending Limit: } \\
\$ 6,700 \text { In- } \\
\text { Network } \\
\text { ( })\end{array}$ & $\begin{array}{l}\text { All Your Drugs on } \\
\text { Formulary: No } \\
\text { Drug Restrictions: } \\
\text { No } \\
\text { No Additional Gap } \\
\text { Coverage } \\
\text { Lower Your Drug } \\
\text { Costs } \\
\text { MTM Program [?]: } \\
\text { Yes }\end{array}$ & $\$ 4,200$ & $\begin{array}{l}k \pi k \star 7 \\
4.5 \text { out of } 5 \\
\text { stars }\end{array}$ & Enroll \\
\hline
\end{tabular}


Figure 3: Implications of Kinked Demand Curve for Equilibrium Premiums and Benefits

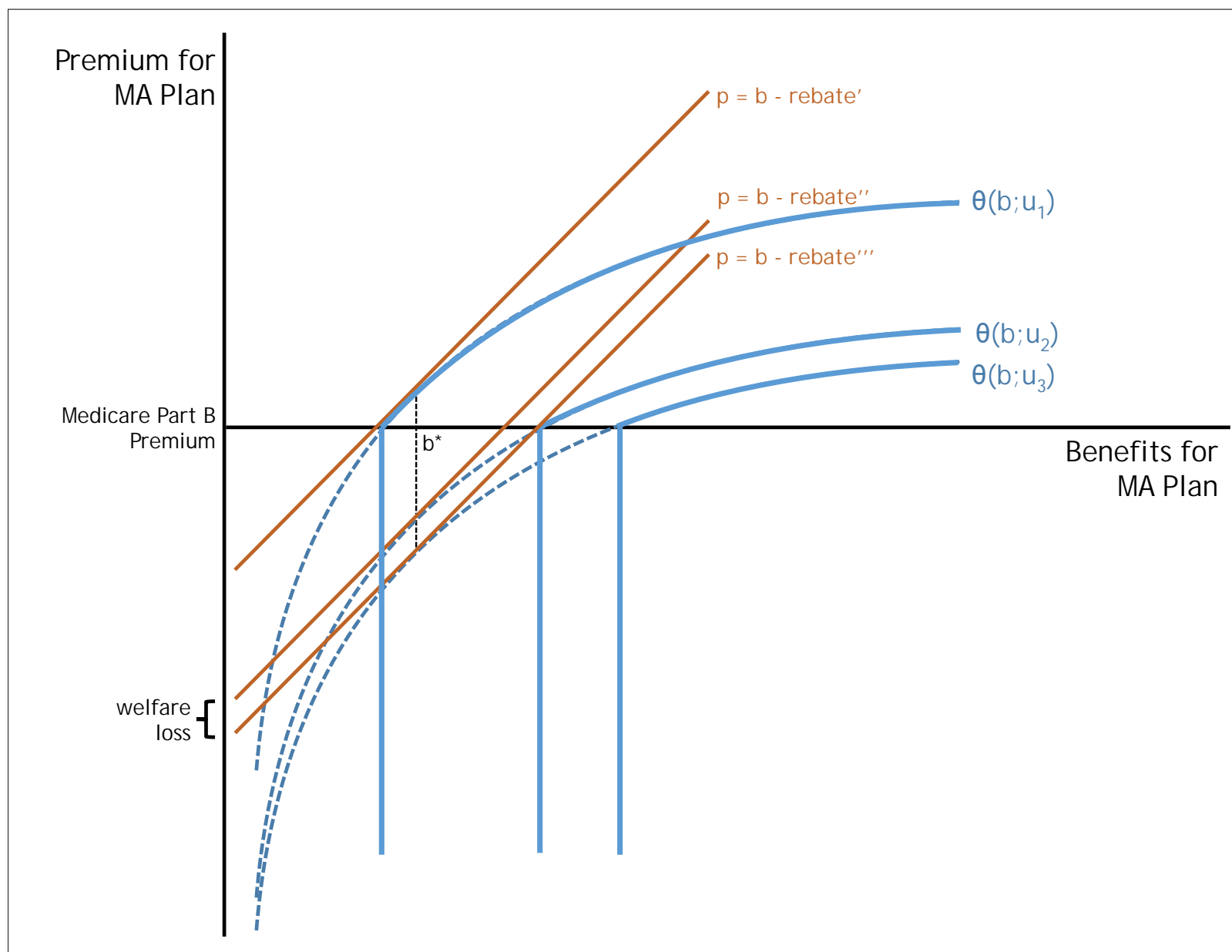


Table 1: Weighted Statistics: Analysis Sample

\begin{tabular}{lcccc}
\hline \hline & 2006 & 2007 & 2008 & 2009 \\
\hline \hline Plan Benchmark & 786.28 & 826.23 & 847.76 & 878.69 \\
Plan Bid & 648.31 & 704.30 & 709.66 & 727.74 \\
Plan Rebate & 88.79 & 87.91 & 100.11 & 110.35 \\
Total Plan Premium & 114.09 & 126.54 & 127.49 & 126.53 \\
Pt C\&D Premium & 26.98 & 34.39 & 32.41 & 32.13 \\
Plan Premium = Pt B Premium & 0.55 & 0.53 & 0.52 & 0.52 \\
Plan Premium < Pt B Premium & 0.03 & 0.03 & 0.03 & 0.05 \\
Plan Premium > Pt B Premium & 0.42 & 0.44 & 0.45 & 0.42 \\
HMO & 0.95 & 0.95 & 0.91 & 0.88 \\
PPO & 0.05 & 0.05 & 0.09 & 0.12 \\
OOPC & - & - & 124.52 & 118.91 \\
\hline $\mathrm{N}$ & 1085 & 1085 & 1461 & 1461 \\
\hline
\end{tabular}

Note: Subsetted to plans bidding below the benchmark. Weighted by plan enrollment.

Table 2: Unweighted Summary Statistics: Analysis Sample

\begin{tabular}{lcccc}
\hline \hline & 2006 & 2007 & 2008 & 2009 \\
\hline \hline Plan Benchmark & 764.22 & 799.16 & 822.58 & 853.17 \\
Plan Bid & 651.27 & 687.33 & 697.40 & 718.26 \\
Plan Rebate & 79.41 & 83.49 & 98.54 & 103.92 \\
Total Plan Premium & 121.52 & 126.34 & 125.25 & 126.69 \\
Pt C\&D Premium & 37.67 & 36.26 & 33.31 & 34.78 \\
Plan Premium = Pt B Premium & 0.37 & 0.40 & 0.40 & 0.41 \\
Plan Premium < Pt B Premium & 0.06 & 0.05 & 0.09 & 0.08 \\
Plan Premium > Pt B Premium & 0.57 & 0.54 & 0.51 & 0.50 \\
HMO & 0.81 & 0.81 & 0.78 & 0.78 \\
PPO & 0.19 & 0.19 & 0.22 & 0.22 \\
OOPC & - & - & 131.70 & 129.37 \\
\hline $\mathrm{N}$ & 1085 & 1085 & 1461 & 1461 \\
\hline
\end{tabular}

Note: Subsetted to plans bidding below the benchmark. 
Table 3: Rebate Results

\begin{tabular}{|c|c|c|c|c|}
\hline VARIABLES & (1) & $(2)$ & $(3)$ & $(4)$ \\
\hline $\mathrm{BENCH}$ & $\begin{array}{c}0.388^{* * *} \\
(0.076)\end{array}$ & $\begin{array}{c}0.394^{* * *} \\
(0.084)\end{array}$ & $\begin{array}{c}0.385^{* * *} \\
(0.085)\end{array}$ & $\begin{array}{c}0.389 * * * \\
(0.080)\end{array}$ \\
\hline FFS SPENDING & & $\begin{array}{c}0.014 \\
(0.051)\end{array}$ & $\begin{array}{c}0.014 \\
(0.051)\end{array}$ & $\begin{array}{c}0.019 \\
(0.048)\end{array}$ \\
\hline INSURERS & & & & $\begin{array}{l}-1.087 \\
(1.522)\end{array}$ \\
\hline Observations & 2,537 & 2,537 & 2,537 & 2,537 \\
\hline R-squared & 0.096 & 0.096 & 0.102 & 0.104 \\
\hline Year FE & YES & YES & YES & YES \\
\hline Plan Type $\times$ Year FE & NO & NO & YES & YES \\
\hline
\end{tabular}

Note: Regressions weighted by mean plan enrollment, standard errors clustered at the plan level.

Table 4: Total Premium (Parts B, C, and D) Results

\begin{tabular}{lcccc}
\hline VARIABLES & $(1)$ & $(2)$ & $(3)$ & $(4)$ \\
BENCH & & & & \\
& & & & \\
FFS SPENDING & $(0.048)$ & $(0.056)$ & $(0.057)$ & $(0.054)$ \\
& & 0.017 & 0.017 & 0.016 \\
INSURERS & & $(0.028)$ & $(0.028)$ & $(0.025)$ \\
& & & & 0.208 \\
Observations & & & & $(1.183)$ \\
R-squared & 2,537 & 2,537 & 2,537 & 2,537 \\
& 0.083 & 0.084 & 0.084 & 0.085 \\
Year FE &. &. &. &. \\
Plan Type $\times$ Year FE & YES & YES & YES & YES \\
\hline
\end{tabular}

Robust standard errors in parentheses

$* * * \mathrm{p}<0.01, * * \mathrm{p}<0.05, * \mathrm{p}<0.1$

Note: Regressions weighted by mean plan enrollment, standard errors clustered at the plan level. 
Table 5: Out-of-Pocket Costs (OOPC) Results (2008-2009 only)

\begin{tabular}{lcccc}
\hline & $(1)$ & $(2)$ & $(3)$ & $(4)$ \\
VARIABLES & & & & \\
\hline \multirow{2}{*}{ BENCH } & $-0.157^{*}$ & $-0.159^{*}$ & $-0.150^{*}$ & -0.141 \\
& $(0.088)$ & $(0.089)$ & $(0.090)$ & $(0.089)$ \\
FFS SPENDING & & -0.007 & -0.007 & -0.002 \\
& & $(0.045)$ & $(0.045)$ & $(0.044)$ \\
INSURERS & & & & 0.686 \\
& & & & $(0.970)$ \\
Observations & 1,461 & 1,461 & 1,461 & 1,461 \\
R-squared & 0.042 & 0.042 & 0.055 & 0.056 \\
& $\cdot$ & $\cdot$ & $\cdot$ & $\cdot$ \\
Year FE & YES & YES & YES & YES \\
Plan Type $\times$ Year FE & NO & NO & YES & YES \\
\hline \multicolumn{4}{c}{ Robust standard errors in parentheses } \\
$* * *$ p $<0.01, * *$ p $<0.05, *$ p $<0.1$ &
\end{tabular}

Note: Regressions weighted by mean plan enrollment, standard errors clustered at the plan level.

Table 6: Rebate Results by Non-Zero Premium Status

\begin{tabular}{|c|c|c|c|}
\hline VARIABLES & (1) & $(2)$ & $\begin{array}{c}(3) \\
\text { Drop Outliers }\end{array}$ \\
\hline BENCH & $\begin{array}{c}0.389^{* * *} \\
(0.080)\end{array}$ & $\begin{array}{c}0.346^{* * *} \\
(0.086)\end{array}$ & $\begin{array}{c}0.343^{* * *} \\
(0.086)\end{array}$ \\
\hline BENCH*NONZERO & & $\begin{array}{c}0.410^{* *} \\
(0.189)\end{array}$ & $\begin{array}{c}0.276 \\
(0.180)\end{array}$ \\
\hline FFS SPENDING & $\begin{array}{c}0.019 \\
(0.048)\end{array}$ & $\begin{array}{c}-0.001 \\
(0.048)\end{array}$ & $\begin{array}{c}-0.003 \\
(0.049)\end{array}$ \\
\hline INSURERS & $\begin{array}{l}-1.087 \\
(1.522)\end{array}$ & $\begin{array}{l}-1.316 \\
(1.486)\end{array}$ & $\begin{array}{l}-1.647 \\
(1.387)\end{array}$ \\
\hline Observations & 2,537 & 2,537 & 2,532 \\
\hline R-squared & 0.104 & 0.133 & 0.128 \\
\hline Year FE & YES & YES & YES \\
\hline Plan Type $\times$ Year FE & YES & YES & YES \\
\hline Plan Type $\times$ Year $\times$ NONZERO FE & NO & YES & YES \\
\hline
\end{tabular}

Note: NONZERO indicates the plan had a positive Part $\mathrm{C}+\mathrm{Part} \mathrm{D}$ premium in the base year. 
Table 7: Total Premium Results by Non-Zero Premium Status

\begin{tabular}{lccc}
\hline VARIABLES & $(1)$ & $(2)$ & $\begin{array}{c}(3) \\
\text { Drop Outliers }\end{array}$ \\
\hline & & & \\
BENCH & -0.062 & 0.016 & 0.019 \\
& $(0.054)$ & $(0.038)$ & $(0.037)$ \\
BENCH*NONZERO & & $-0.625^{* * *}$ & $-0.451^{* * *}$ \\
& & $(0.202)$ & $(0.164)$ \\
FFS SPENDING & 0.016 & 0.025 & 0.027 \\
& $(0.025)$ & $(0.026)$ & $(0.026)$ \\
INSURERS & 0.208 & 1.012 & 1.452 \\
& $(1.183)$ & $(1.149)$ & $(1.008)$ \\
Observations & & & \\
R-squared & 2,537 & 2,537 & 2,532 \\
& 0.085 & 0.127 & 0.147 \\
Year FE & $\cdot$ & $\cdot$ & $\cdot$ \\
Plan Type $\times$ Year FE & YES & YES & YES \\
Plan Type $\times$ Year $\times$ NONZERO FE & NO & YES & YES \\
\hline \multicolumn{4}{c}{ Robust standard errors in parentheses } \\
*** $<<0.01, * *$ p $<0.05, *$ p $<0.1$ &
\end{tabular}

Note: NONZERO indicates the plan had a positive Part C+Part D premium in the base year. 
Table 8: Rebate Results by Subsample

\begin{tabular}{|c|c|c|c|}
\hline VARIABLES & $\begin{array}{c}(1) \\
2006-2007\end{array}$ & 2008-2009 & $\begin{array}{c}(3) \\
2006-2007 \\
2008-2009\end{array}$ \\
\hline BENCH & $\begin{array}{c}0.096 \\
(0.148)\end{array}$ & $\begin{array}{c}0.416^{* * *} \\
(0.076)\end{array}$ & $\begin{array}{c}0.346^{* * *} \\
(0.086)\end{array}$ \\
\hline BENCH*NONZERO & $\begin{array}{c}0.711^{* * *} \\
(0.249)\end{array}$ & $\begin{array}{l}-1.322 \\
(0.841)\end{array}$ & $\begin{array}{c}0.410^{* *} \\
(0.189)\end{array}$ \\
\hline FFS SPENDING & $\begin{array}{c}0.040 \\
(0.068)\end{array}$ & $\begin{array}{l}-0.039 \\
(0.045)\end{array}$ & $\begin{array}{l}-0.001 \\
(0.048)\end{array}$ \\
\hline INSURERS & $\begin{array}{l}-1.305 \\
(1.324)\end{array}$ & $\begin{array}{l}-1.701 \\
(1.085)\end{array}$ & $\begin{array}{l}-1.316 \\
(1.486)\end{array}$ \\
\hline $\begin{array}{l}\text { Observations } \\
\text { R-squared }\end{array}$ & $\begin{array}{l}1,076 \\
0.082\end{array}$ & $\begin{array}{l}1,461 \\
0.223\end{array}$ & $\begin{array}{l}2,537 \\
0.133\end{array}$ \\
\hline Year FE & YES & YES & YES \\
\hline Plan Type $\times$ Year FE & YES & YES & YES \\
\hline Plan Type $\times$ Year $\times$ NONZERO FE & YES & YES & YES \\
\hline
\end{tabular}

Note: NONZERO indicates the plan had a positive Part $\mathrm{C}+$ Part $\mathrm{D}$ premium in the base year. 
Table 9: Total Premium Results by Subsample

\begin{tabular}{|c|c|c|c|}
\hline VARIABLES & $\begin{array}{c}(1) \\
2006-2007\end{array}$ & $\begin{array}{c}(2) \\
2008-2009\end{array}$ & $\begin{array}{c}(3) \\
2006-2007 \\
2008-2009\end{array}$ \\
\hline BENCH & $\begin{array}{c}0.061 \\
(0.096)\end{array}$ & $\begin{array}{l}-0.003 \\
(0.010)\end{array}$ & $\begin{array}{c}0.016 \\
(0.038)\end{array}$ \\
\hline BENCH*NONZERO & $\begin{array}{c}-0.670^{* * *} \\
(0.222)\end{array}$ & $\begin{array}{l}-0.129 \\
(0.370)\end{array}$ & $\begin{array}{c}-0.625^{* * *} \\
(0.202)\end{array}$ \\
\hline FFS SPENDING & $\begin{array}{c}0.042 \\
(0.041)\end{array}$ & $\begin{array}{c}0.008 \\
(0.015)\end{array}$ & $\begin{array}{c}0.025 \\
(0.026)\end{array}$ \\
\hline INSURERS & $\begin{array}{c}0.920 \\
(1.015)\end{array}$ & $\begin{array}{c}0.731 \\
(0.580)\end{array}$ & $\begin{array}{c}1.012 \\
(1.149)\end{array}$ \\
\hline $\begin{array}{l}\text { Observations } \\
\text { R-squared }\end{array}$ & $\begin{array}{l}1,076 \\
0.150\end{array}$ & $\begin{array}{l}1,461 \\
0.033\end{array}$ & $\begin{array}{l}2,537 \\
0.127\end{array}$ \\
\hline Year FE & YES & YES & YES \\
\hline Plan Type $\times$ Year FE & YES & YES & YES \\
\hline Plan Type $\times$ Year $\times$ NONZERO FE & YES & YES & YES \\
\hline
\end{tabular}

Note: NONZERO indicates the plan had a positive Part $\mathrm{C}+\mathrm{Part} \mathrm{D}$ premium in the base year. 
Table 10: Out-of-Pocket Costs (OOPC) Results by Non-Zero Premium Status (2008-2009 only)

\begin{tabular}{|c|c|c|}
\hline VARIABLES & (1) & $(2)$ \\
\hline BENCH & $\begin{array}{l}-0.141 \\
(0.089)\end{array}$ & $\begin{array}{l}-0.133 \\
(0.093)\end{array}$ \\
\hline BENCH*NONZERO & & $\begin{array}{c}0.871 \\
(0.648)\end{array}$ \\
\hline FFS SPENDING & $\begin{array}{l}-0.002 \\
(0.044)\end{array}$ & $\begin{array}{l}-0.009 \\
(0.046)\end{array}$ \\
\hline INSURERS & $\begin{array}{c}0.686 \\
(0.970)\end{array}$ & $\begin{array}{c}0.115 \\
(1.000)\end{array}$ \\
\hline Observations & 1,461 & 1,461 \\
\hline R-squared & 0.056 & 0.069 \\
\hline Year FE & YES & YES \\
\hline Plan Type $\times$ Year FE & YES & YES \\
\hline Plan Type $\times$ Year $\times$ NONZERO FE & NO & YES \\
\hline
\end{tabular}

Note: NONZERO indicates the plan had a positive Part C+Part D premium in 2008. 


\section{References}

Abaluck, Jason and Jonathan Gruber, "Choice Inconsistencies among the Elderly: Evidence from Plan Choice in the Medicare Part D Program," American Economic Review, 2011, 101 (4), 1180-1210.

Biles, Brian, Jonah Pozen, and Stuart Gutterman, "The Continuing Cost of Privatization: Extra Payments to Medicare Advantage Plans Jump to $\$ 11.4$ Billion in 2009," Technical Report pub. 1265, The Commonwealth Fund, www.commonwealthfund.org May 2009.

Centers for Medicare \& Medicaid Services, "FFS Data (2008-2010)," 2008-2009. Available from http://www.cms.gov/Medicare/Health-Plans/MedicareAdvtgSpecRateStats/FFS_ Data.html.

_, "Medicare Advantage/Part D Contract and Enrollment Data," 2008-2009. Available from http://www.cms.gov/Research-Statistics-Data-and-Systems/ Statistics-Trends-and-Reports/MCRAdvPartDEnrolData/index.html.

-, "Plan Crosswalks," 2008-2009. Available from http://www.cms.gov/ Research-Statistics-Data-and-Systems/Statistics-Trends-and-Reports/ MCRAdvPartDEnrolData/Plan-Crosswalks.html.

-, "Plan Payment Data," 2008-2009. Available from http://www.cms.gov/Medicare/ Medicare-Advantage/Plan-Payment/Plan-Payment-Data.html.

_, "Ratebooks \& Supporting Data," 2008-2009. Available from http://www.cms.gov/Medicare/ Health-Plans/MedicareAdvtgSpecRateStats/Ratebooks-and-Supporting-Data.html.

Chernew, Michael E, Philip DeCicca, and Robert Town, "Managed Care and Medical Expenditures of Medicare Beneficiaries," Journal of Health Economics, 2008, 27 (6), 1451-1461.

Congressional Budget Office, "Medicare - May 2013 Baseline," May 2013. Available from http://www. cbo.gov/publication/44205.

Duggan, Mark, Amanda Starc, and Boris Vabson, "Who Benefits When the Government Pays More? Pass-Through in the Medicare Advantage Program," NBER working paper, March 2014.

Dunn, Abe, "The value of coverage in the medicare advantage insurance market," Journal of Health Economics, December 2010, 29 (6), 839-855.

Frakt, Austin B, Steven D Pizer, and Roger Feldman, "The Effects of Market Structure and Payment Rate on the Entry of Private Health Plans into the Medicare Market," Inquiry, Spring 2012, 49 (1), 15-36. 
Glazer, Jacob and Thomas G McGuire, "Optimal Risk Adjustment in Markets with Adverse Selection: An Application to Managed Care," American Economic Review, 2000, 90 (4), 10551071.

Gold, Marsha, Gretchen Jacobson, Anthony Damico, and Tricia Neuman, "Medicare Advantage 2012 Data Spotlight: Enrollment Market Update," Technical Report, Kaiser Family Foundation 2012.

_ , _ , _, and _, "Medicare Advantage 2014 Spotlight: Plan Availability And Premiums," Technical Report, Kaiser Family Foundation 2013.

Jacobson, Gretchen, Tricia Neuman, Anthony Damico, and Jennifer Huang, "Medicare Advantage Plan Star Ratings and Bonus Payments in 2012," Technical Report, Kaiser Family Foundation, publication 8257 November 2011.

McGuire, Thomas G, Joseph P Newhouse, and Anna D Sinaiko, "An Economic History of Medicare Part C," The Milbank Quarterly, 2011, 89 (2), 289-332.

McWilliams, J Michael, Christopher C Afendulis, Thomas G McGuire, and Bruce E Landon, "Complex Medicare Advantage Choices May Overwhelm Seniors-Especially Those With Impaired Decision Making," Health Affairs, 2011, 30 (9), 1786-1794.

_ , John Hsu, and Joseph P Newhouse, "New Risk-Adjustment System Was Associated With Reduced Favorable Selection In Medicare Advantage," Health Affairs, 2012, 31 (12), 2630-2640.

Medicare Payment Advisory Commission, "Report to the Congress: Improving Risk Adjustment in Medicare," November 2000.

_ , "Medicare Advantage Program Payment System," October 2011. Available from www.medpac. gov/documents/MedPAC_Payment_Basics_11_MA.pdf, accessed February 8, 2013.

_ , "Report to the Congress: Medicare Payment Policy," March 2012. Available from www .medpac . gov/chapters/Mar12_Ch12.pdf, accessed March 31, 2014.

Morgan, Robert O, Beth A Virnig, Carolee A DeVito, and Nancy A Persily, "The Medicare-HMO Revolving Door - The Healthy Go in and the Sick Go Out," New England Journal of Medicine, 1997, 337 (3), 169-175.

Newhouse, Joseph P and Thomas G McGuire, "How Successful Is Medicare Advantage?," The Milbank Quarterly, 2014, forthcoming.

_, Jie Huang, Richard J Brand, Vicki Fung, and John Hsu, "The Structure of Risk Adjustment for Private Plans in Medicare," American Journal of Managed Care, 2011, 17 (6), e231-e240. 
_, Mary Price, Jie Huang, J Michael McWilliams, and John Hsu, "Steps To Reduce Favorable Risk Selection In Medicare Advantage Largely Succeeded, Boding Well For Health Insurance Exchanges," Health Affairs, 2012, 31 (12), 2618-2628.

Pizer, Steven D, Austin B Frakt, and Roger Feldman, "Payment Policy and Inefficient Benefits in the Medicare+Choice Program," International Journal of Health Care Finance and Economics, 2003, 3 (2), 79-93.

Rosen, Sherwin, "Hedonic Prices and Implicit Markets: Product Differentiation in Pure Competition," Journal of Political Economy, 1974, 82 (1), 34-55.

Rothschild, Michael and Joseph Stiglitz, "Equilibrium in Competitive Insurance Markets: An Essay on the Economics of Imperfect Information," Quarterly Journal of Economics, 1976, $90(4), 629-649$.

Song, Zirui, Mary Beth Landrum, and Michael E Chernew, "Competitive Bidding in Medicare: Who Benefits From Competition?," American Journal of Managed Care, 2012, 18 (9), $546-552$.

_, _, and _, "Competitive bidding in Medicare Advantage: Effect of benchmark changes on plan bids," Journal of Health Economics, 2013, 32 (6), 1301-1312.

\section{A Additional Figures and Tables}


Figure A.1: Relationship Between Changes in Plan Benchmarks and Changes in Realized FFS Medicare Spending in the Plan's Service Area

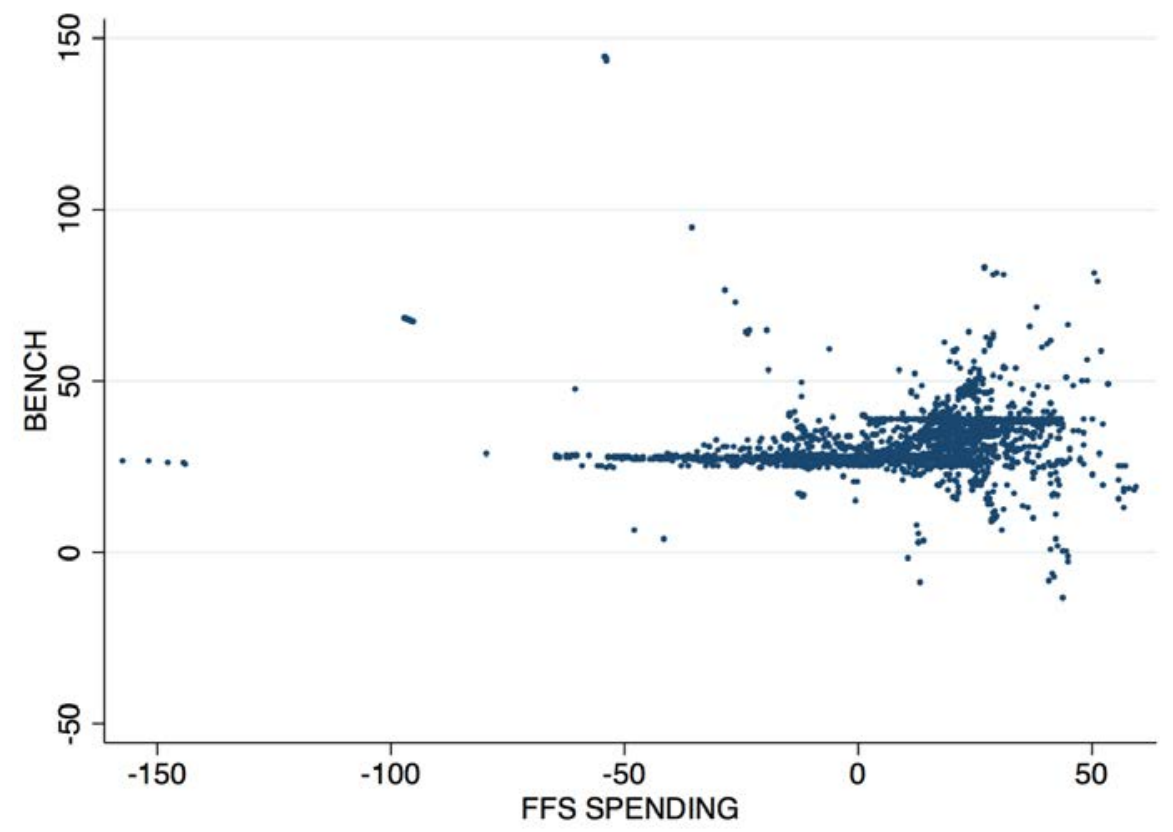

Source: Plan-level analysis sample of first-differenced 2007 and 2009 data, described in the text.

Table A.1: Number of Plans by Plan Type

\begin{tabular}{lcccc}
\hline \hline & 2006 & 2007 & 2008 & 2009 \\
\hline \hline HMO & 982 & 1,225 & 1,185 & 1,385 \\
PPO & 259 & 264 & 335 & 474 \\
PFFS & 123 & 284 & 582 & 706 \\
\hline $\mathrm{N}$ & 1364 & 1773 & 2102 & 2565
\end{tabular}

Note: Subsetted to plans bidding below the benchmark.

Table A.2: Unweighted Entry and Exit Rates by Plan Type

\begin{tabular}{lcccc}
\hline \hline & 2006 & 2007 & 2008 & 2009 \\
\hline \hline & Exit & Entry & Exit & Entry \\
HMO & 0.07 & 0.22 & 0.03 & 0.15 \\
PPO & 0.09 & 0.14 & 0.03 & 0.25 \\
PFFS & 0.00 & 0.63 & 0.06 & 0.17 \\
\hline $\mathrm{N}$ & 1364 & 1773 & 2102 & 2565
\end{tabular}

Note: Subsetted to plans bidding below the benchmark. 
Table A.3: Weighted Entry and Exit Rates by Plan Type

\begin{tabular}{lcccc}
\hline \hline & 2006 & 2007 & 2008 & 2009 \\
\hline \hline & Exit & Entry & Exit & Entry \\
HMO & 0.02 & 0.03 & 0.00 & 0.02 \\
PPO & 0.06 & 0.08 & 0.00 & 0.08 \\
PFFS & 0.00 & 0.38 & 0.12 & 0.04 \\
\hline $\mathrm{N}$ & 1364 & 1773 & 2102 & 2565
\end{tabular}

Note: Subsetted to plans bidding below the benchmark. Weighted by plan enrollment.

Table A.4: Weighted Summary Statistics of Unrestricted Sample

\begin{tabular}{lcccc}
\hline \hline & 2006 & 2007 & 2008 & 2009 \\
\hline \hline Plan Benchmark & 785.36 & 825.36 & 847.61 & 877.92 \\
Plan Bid & 653.78 & 702.63 & 710.28 & 727.29 \\
Plan Rebate & 84.52 & 89.03 & 99.56 & 110.45 \\
Total Plan Premium & 117.64 & 125.79 & 128.00 & 126.54 \\
Pt C\&D Premium & 31.33 & 33.70 & 32.90 & 32.15 \\
Plan Premium = Pt B Premium & 0.51 & 0.53 & 0.51 & 0.52 \\
Plan Premium < Pt B Premium & 0.03 & 0.03 & 0.03 & 0.05 \\
Plan Premium > Pt B Premium & 0.45 & 0.44 & 0.45 & 0.42 \\
HMO & 0.95 & 0.95 & 0.91 & 0.87 \\
PPO & 0.05 & 0.05 & 0.09 & 0.13 \\
OOPC & - & - & 124.74 & 118.82 \\
\hline N & 1241 & 1489 & 1520 & 1859
\end{tabular}

Note: Subsetted to plans bidding below the benchmark. Weighted by plan enrollment. 